OPEN ACCESS

Edited by:

Nam-Chon Paek,

Seoul National University,

South Korea

Reviewed by:

Jing Bo Jin,

Chinese Academy of Sciences,

China

Miguel A Botella,

University of Málaga,

Spain

*Correspondence:

Jae-Yean Kim

kimjy@gnu.ac.kr

Dae-Jin Yun

djyun@konkuk.ac.kr

tThese authors have contributed equally to this work

Specialty section:

This article was submitted to

Plant Abiotic Stress,

a section of the journal

Frontiers in Plant Science

Received: 09 May 2019 Accepted: 22 August 2019 Published: 11 October 2019

Citation:

Baek D, Kim MC, Kumar D, Park B,

Cheong MS, Choi W, Park HC,

Chun HJ, Park HJ, Lee SY,

Bressan RA, Kim J-Y and Yun D-J

(2019) AtPR5K2, a PR5-Like

Receptor Kinase, Modulates Plant

Responses to Drought Stress by

Phosphorylating Protein

Phosphatase 2Cs.

Front. Plant Sci. 10:1146.

doi: 10.3389/fp/s.2019.01146

\section{AtPR5K2, a PR5-Like Receptor Kinase, Modulates Plant Responses to Drought Stress by Phosphorylating Protein Phosphatase 2Cs}

\author{
Dongwon Baek ${ }^{1 \dagger}$, Min Chul Kim ${ }^{1,2+}$, Dhinesh Kumar ${ }^{1,3 \dagger}$, Bokyung Park ${ }^{4}$, Mi Sun Cheong ${ }^{1,2}$, \\ Wonkyun Choi ${ }^{5}$, Hyeong Cheol Park ${ }^{5}$, Hyun Jin Chun², Hee Jin Park ${ }^{6,7}$, \\ Sang Yeol Lee ${ }^{1}$, Ray A. Bressan ${ }^{8}$, Jae-Yean Kim ${ }^{1 *}$ and Dae-Jin Yun ${ }^{6 *}$
}

1 Division of Applied Life Science (BK21plus program), Plant Molecular Biology and Biotechnology Research Center, Gyeongsang National University, Jinju, South Korea, ${ }^{2}$ Institute of Agriculture \& Life Science, Gyeongsang National University, Jinju, South Korea, ${ }^{3}$ Donald Danforth Plant Science Center, St Louis, MO, United States, ${ }^{4}$ Gyeongsangnam-do Agricultural Research and Extension Services, Jinju, South Korea, ${ }^{5}$ Division of Ecological Conservation, Bureau of Ecological Research, National Institute of Ecology (NIE), Seocheon, South Korea, ${ }^{6}$ Department of Biomedical Science and Engineering, Konkuk University, Seoul, South Korea, 7 Institute of Glocal Disease Control, Konkuk University, Seoul, South Korea, ${ }^{8}$ Department of Horticulture and Landscape Architecture, Purdue University, West Lafayette, IN, United States

Cell surface receptors perceive signals from the environment and transfer them to the interior of the cell. The Arabidopsis thaliana PR5 receptor-like kinase (AtPR5K) subfamily consists of three members with extracellular domains that share sequence similarity with the PR5 proteins. In this study, we characterized the role of AtPR5K2 in plant droughtstress signaling. AtPR5K2 is predominantly expressed in leaves and localized to the plasma membrane. The atpr5k2-1 mutant showed tolerance to dehydration stress, while AtPR5K2-overexpressing plants was hypersensitive to drought. Bimolecular fluorescence complementation assays showed that AtPR5K2 physically interacted with the type $2 \mathrm{C}$ protein phosphatases $A B A$-insensitive $1(\mathrm{ABI} 1)$ and $\mathrm{ABI} 2$ and the SNF1-related protein kinase 2 (SnRK2.6) proteins, all of which are involved in the initiation of abscisic acid (ABA) signaling; however, these interactions were inhibited by treatments of exogenous $A B A$. Moreover, AtPR5K2 was found to phosphorylate ABI1 and ABI2, but not SnRK2.6. Taken together, these results suggest that AtPR5K2 participates in ABA-dependent droughtstress signaling through the phosphorylation of $\mathrm{ABl} 1$ and $\mathrm{ABI}$.

Keywords: drought stress, abscisic acid, receptor-like kinase, ABI1, ABI2, SnRK2.6, phosphorylation, Arabidopsis thaliana

\section{INTRODUCTION}

Plant receptors perceive signals from external stimuli and transmit this information to the interior of the cell (McCarty and Chory, 2000). These receptors are typically composed of three major domains: an external ligand-binding domain for detecting the signal, a transmembrane domain for anchoring to the cell membrane, and an intracellular domain for transmitting the signal inside the cell to generate a signaling cascade (Hohmann et al., 2017). To sense and transmit the vast numbers of signals arising from environmental stimuli, plants have functionally evolved a large family of membrane receptor kinases and receptor-like kinases (RLKs) (Shiu and Bleecker, 2001; Hohmann et al., 2017). 
In the Arabidopsis thaliana genome, the RLKs are represented by 610 proteins divided into 44 subfamilies and at least 16 types, which have unique extracellular domain structures and functions (Shiu and Bleecker, 2001). Plant RLKs have different functions according to the types of motifs in their extracellular domains (Shiu and Bleecker, 2001); for example, the extracellular domains of leucine-rich repeat RLKs (LRR-RLKs) play important roles in the protein-protein interactions required for various signal transduction pathways in plant growth and development (Kobe and Deisenhofer, 1994; Torii et al., 1996; Clark et al., 1997; Yokoyama et al., 1998; Schoof et al., 2000; Mandel et al., 2016). The S-receptor kinases (SRKs) that possess a membrane-spanning serine/threonine kinase motif are involved in the determination of pollen-derived S-haplotype specificity for self-incompatibility (Hatakeyama et al., 2001; Takayama and Isogai, 2003). The lectin RLKs interact with extracellular carbohydrates such as glucose, mannose, fructose, chitobiose, and other sugars, and play roles in plant developmental processes and the signaling responses to plant hormones during various abiotic and biotic stresses (Loris et al., 2003; Vaid et al., 2012; Yang et al., 2016). The CRINKLY4 (CR4) family of RLKs contain a tumor necrosis factor receptor motif and are required for vegetative growth, floral organ development, aleurone formation in seeds, and sex determination (Becraft et al., 1996; Jin et al., 2000; Kang et al., 2002; Tian et al., 2007; Nikonorova et al., 2015), while the wall-associated kinase family of RLKs possess epidermal growth factor-like domains and are essential regulators of cell expansion, immunity resistance, and heavy metal tolerance in Arabidopsis (Verica and He, 2002; Verica et al., 2003; Hou et al., 2005; Wang et al., 2012). The pathogenesisrelated 5 (PR5) RLKs (PR5Ks) are activated by several hormones and pathogenic infections (Thomma et al., 1998; Clarke et al., 2000; Durrant and Dong, 2004; van Loon et al., 2006).

Osmotin has been classified into the PR5 family with thaumatin-like domain (Abdin et al., 2011). Osmotin has been identified as the predominant protein $(24 \mathrm{kDa}$ protein) from osmotically adapted tobacco cells (Singh et al., 1985; Singh et al., 1987; Yun et al., 1997). In addition, osmotin is synthesized in root in response to exogenous abscisic acid (ABA) and accumulated in the presence of $\mathrm{NaCl}$ (Singh et al., 1987). The osmotin and osmotin-like proteins (OLPs), having antifungal activity, are basic isoform of the thaumatin-like proteins (TLPs) and share highly similar amino acid sequences (Yun et al., 1997; Shiu and Bleecker, 2001; Abdin et al., 2011; Misra et al., 2016). In addition to their common thaumatin-like domain, the OLPs and TLPs contain two additional domains to function, protein kinase-like domains and bifunctional inhibitor/lipid-transfer/seed storage $2 S$ albumin domains (Liu J et al., 2010; Abdin et al., 2011). These proteins have been implicated in a wide range of cellular processes, including enzyme activation, the assembly of macromolecules, the cellular localization of proteins, and protein degradation (Liu J et al., 2010; Abdin et al., 2011). Moreover, the expression of OLP and TLP genes is induced by various environmental stresses, such as pathogens, salt, ABA, drought, cold, and wounding, suggesting that they may also function in stress signaling (Singh et al., 1989; Yun et al., 1998; van Loon et al., 2006; Misra et al., 2016). An in silico analysis of the structural features of these proteins suggested that they bind to specific receptors (Misra et al., 2016); however, the nature of their binding partners and the molecular and phenotypic consequences of such interactions remain unknown.

The phytohormone ABA is associated with diverse processes in plant growth and development, including seed maturation, seed dormancy, stomatal closure, and seedling growth (Finkelstein et al., 2002). ABA also plays major roles in plant-adaptive mechanisms to abiotic stresses such as cold, drought, and salinity, principally by regulating stomatal closure (Zhu, 2002; Raghavendra et al., 2010; Roychoudhury et al., 2013). The protein phosphatase type 2C (PP2C) proteins, including ABA-insensitive 1 (ABI1), ABI2, AtPP2CA/ABA hypersensitive germination 3 (AHG3), AHG1, hypersensitive to $\mathrm{ABA} 1$ ( $\mathrm{HAB} 1$ ), and $\mathrm{HAB} 2$, serve as negative regulators of ABA signaling (Kuhn et al., 2006; Saez et al., 2006; Yoshida et al., 2006b; Fujii et al., 2009a; Nishimura et al., 2009; Nishimura et al., 2010). In the absence of ABA, the activated PP2Cs bind to the SNF1-related protein kinase 2s (SnRK2s) and dephosphorylate their serine residues, preventing them from phosphorylating their targets in the ABA signaling pathway (Yoshida et al., 2006a; Fujii and Zhu, 2009b). ABA signals are detected by the pyrabactin resistance (PYR)/PYR1-like (PYL)/ regulatory component of $\mathrm{ABA}$ receptor (RCAR) proteins, key $\mathrm{ABA}$ receptors that activate $\mathrm{ABA}$ signaling by binding both the ABA molecule and the PP2C proteins to inhibit the phosphatase activity of the PP2Cs (Fujii et al., 2009a; Park et al., 2009; Nishimura et al., 2010; Gonzalez-Guzman et al., 2012; Lee et al., 2013). This releases the SnRK2s from the PP2Cs-SnRK2s complex, which enables them to be activated by autophosphorylation and/or phosphorylation by other kinases (Melcher et al., 2009; Yin et al., 2009). The activated SnRK2s phosphorylate and activate several transcription factors involved in ABA signal transduction, such as the ABRE binding factor (ABF) transcription factors (Umezawa et al., 2009b; Xie et al., 2012). The core components, including the PYLs, PP2Cs, and SnRK2s, form a signaling complex known as the "ABA signalosome" or "ABA core signaling module" (Umezawa et al., 2009a and Umezawa et al., 2009b); however, the detailed regulation of the $\mathrm{ABA}$ signalosome in RLK-mediated signaling requires further studies.

In plant expressed sequence tag databases, 3 PR5Ks from among 27 proteins in the PR5 family included thaumatin domain in $\mathrm{N}$-terminal region (Liu J et al., 2010). Here, we characterized the roles of the three Arabidopsis PR5-like receptor kinases (AtPR5Ks) in ABAdependent drought-stress response. The atpr5k2-1 mutant was found to be hypersensitive to drought stress but resistant to exogenous ABA stress. We revealed that AtPR5K2 acts as a negative regulator of ABA signaling during drought stress. AtPR5K2 phosphorylates ABI1 and $\mathrm{ABI} 2$ and functions most probably by modulating the phosphatase activity of PP2Cs of the ABA signalosome components.

\section{MATERIALS AND METHODS}

\section{In silico Analysis}

The amino acid sequence analysis programs on TAIR (https:// www.arabidopsis.org/) were used to search for homologous genes. Multiple sequence alignments of proteins were carried out 
using ClustalW (http://www.genome.jp/tools/clustalw) and the Plant Protein Phosphorylation DataBase (http://www.p3db.org).

\section{Plant Materials and Growth Conditions}

The A. thaliana wild type (WT) used in this study was Col-0 ecotype, and all mutant and gene-overexpressing transgenic plants had a Col-0 background. The pr5k1-1 (Salk_142707), pr5k2-1 (GK_321B01), and pr5k3-1 (GABI_254G07) mutants were obtained from the Arabidopsis Biological Resource Center (pr5k1-1) and the GABI collection ( $p r 5 k 2-1$ and pr5k3-1). Homozygous mutants were identified using a genomic PCR analysis with a T-DNA left border primer (LBb1.3) and two pairs of PR5K-specific primers. The sequences of experimental primers used for genotyping the various mutants are described in Supplemental Table 1.

Arabidopsis seeds were sterilized for $5 \mathrm{~min}$ with a $70 \%$ ethanol and 2\% sodium hypochlorite solution (Yakuri pure chemicals, Kyoto, Japan) and then washed five times with sterilized water. After stratification for 3 days at $4^{\circ} \mathrm{C}$ in the dark, the seeds were plated on 1/2-strength Murashige and Skoog (MS) plates ( $\mathrm{pH}$ 5.7) containing $0.6 \%$ agar and $1.5 \%$ sucrose, and grown in a growth chamber with 16-h light/8-h dark photoperiod at $23^{\circ} \mathrm{C}$.

\section{Physiological Assays}

To test drought sensitivity, 3-week-old plants grown in soil with sufficient water were not watered for 11 or 13 days. After rewatering, the recovery of the drought-treated plants was monitored. The drought experiments were repeated four times using at least 12 plants for each line in each experiment. To measure the transpirational water loss, leaves were detached from 4-weekold plants grown in soil and placed on Petri dishes. Their fresh weights were measured periodically at the indicated times and the percentage of water loss. The water loss assays were repeated three times using at least 15 plants for each line in each experiment.

To measure the percentage of cotyledon greening, the seeds of all experimental plants were harvested at the same time and grown on 1/2-strength MS plates ( $\mathrm{pH} 5.7$ ) containing $0.6 \%$ agar and $1.5 \%$ sucrose, without or with different concentrations of ABA (Sigma-Aldrich, St. Louis, MO, USA) and other abiotic stresses such as $\mathrm{NaCl}$, mannitol, $\mathrm{KCl}$, and $\mathrm{LiCl}$. Cotyledon greening was determined after their expansion. The percentage of cotyledon greening was obtained from three biological replications using at least 48 seedlings for each line in each replication.

\section{Generation of PR5K2-Overexpressing Transgenic Plants}

To generate the PR5K2-overexpressing transgenic plants, the full length of $P R 5 K 2$ complementary DNA (cDNA) was amplified from WT using PCR and cloned into $p M D C 83$ gateway vector (Thermo Fisher Scientific, MA, USA), which contained a hygromycin resistance gene and a GFP fusion sequence. Arabidopsis plants were transformed using Agrobacterium tumefaciens-mediated methods (Clough and Bent, 1998). The PR5K2-overexpressing transgenic plants were selected on 1/2 MS medium containing 30 $\mu \mathrm{g} / \mathrm{l}$ of hygromycin (Merck, NJ, USA), and their PR5K2 expression levels were analyzed using reverse transcription PCR (RT-PCR) using gene-specific primers listed in Supplemental Table 1.

\section{Quantitative RT-PCR Analysis}

Total RNA was extracted and purified from different Arabidopsis tissues using the RNeasy Plant Mini Kit (Qiagen, Hilden, Germany), according to the manufacturer's instructions, and treated with DNaseI (Sigma-Aldrich, St. Louis, MO, USA) to remove any genomic DNA contaminants. For the RT-PCR and quantitative RT-PCR (qRT-PCR) analyses, $2 \mu \mathrm{g}$ total RNA was used for cDNA synthesis using SuperScript III (Thermo Fisher Scientific, MA, USA), in accordance with the manufacturer's protocol. The qRTPCR analysis was performed using a SYBR Green Supermix kit (Bio-Rad Laboratories, Hercules, CA, USA), and the relative gene expression levels were automatically calculated using the CFX384 real-time PCR detection system (Bio-Rad Laboratories, Hercules, CA, USA). The qRT-PCR was performed using the following conditions: $95^{\circ} \mathrm{C}$ for $10 \mathrm{~min}$, followed by 50 cycles of $95^{\circ} \mathrm{C}$ for $10 \mathrm{~s}$, $60^{\circ} \mathrm{C}$ for $30 \mathrm{~s}$, and $72^{\circ} \mathrm{C}$ for $30 \mathrm{~s}$. The expression of TUBULIN2 was used as the endogenous control. The qRT-PCR experiments were performed in three independent replicates. The gene-specific primers used are listed in Supplemental Table 1.

\section{Transient Assays to Determine the Subcellular Localization of PR5K2}

The full-length PR5K2 cDNA was cloned into the XbaI and $B a m \mathrm{HI}$ sites of a superfolder green fluorescent protein (sGFP) vector plasmid containing the sGFP to create a chimeric GFPfusion construct under the control of the CaMV $35 S$ promoter. To investigate the subcellular localization of PR5K2, PR5K2sGFP was introduced into Arabidopsis protoplasts using a polyethylene glycol-mediated transformation (Baek et al., 2013). To confirm the localization of PR5K2 in the plasma membrane, the $p M D C 83$ vector containing PR5K2-GFP was transformed into $A$. tumefaciens (GV3101 strain). The transformed cells were infiltrated into the leaves of 3-weekold tobacco (Nicotiana benthamiana) plants. The PR5K2GFP-infiltrated leaves were plasmolyzed by cutting them into small pieces and soaking them in an enzyme solution including osmoticum (mannitol and $\mathrm{MgSO}_{4}$ ) and a protectant $\left(\mathrm{CaCl}_{2}\right)$ for $1 \mathrm{~h}$. The fluorescent signals were detected using GFP filter (excitation, $488 \mathrm{~nm}$; emission, $510 \mathrm{~nm}$ ) and RFP filter (excitation, $543 \mathrm{~nm}$; emission, $581 \mathrm{~nm}$ ) on a confocal laser-scanning microscope (Olympus FV1000; Olympus, Tokyo, Japan). The wavelength range of bright field was in 30 $\mathrm{nm}$ for GFP and $100 \mathrm{~nm}$ for RFP. The confocal lasers were used argon for GFP and Green HeNe for RFP.

\section{Kinase Assays}

The sequences of the PR5K2 kinase domain (wPR5K2KD) and the mutagenized PR5K2 kinase domain (mPR5K2KD) were amplified from full-length PR5K2 using PCR and sequencespecific primers. The mPR5K2KD kinase domain was generated using site-directed mutagenesis methods that converted the lysine residue of the kinase domain to alanine. The $w P R 5 K 2 K D$ and $m P R 5 K 2 K D$ sequences were cloned into the EcoRI and SalI sites of the $p G E X 5 X-1$ vector, which provided the GST expression. The GST-fused recombinant proteins were expressed in Escherichia coli (BL21 strain) and purified using glutathione sepharose 4B (GE Healthcare, Chicago, IL, USA), according to the manufacturer's 
instructions. GST proteins were used as a control. For the in vitro autophosphorylation assays, $2 \mu \mathrm{g}$ of the recombinant protein was incubated at $30^{\circ} \mathrm{C}$ for $30 \mathrm{~min}$ in a kinase buffer containing $20 \mathrm{mM}$ 4-(2-hydroxyethyl)-1-piperazineethanesulfonic acid ( $\mathrm{pH}$ 7.5), $20 \mathrm{mM} \mathrm{MgCl}, 2 \mathrm{mM} \mathrm{MnCl}$, and $1 \mu \mathrm{Ci}$ of $[\gamma-32 \mathrm{P}]$ ATP $(3,000 \mathrm{Ci} / \mathrm{mmol})$. After separating the reaction products on a $10 \%$ polyacrylaminde gel using sodium dodecyl sulfate polyacrylamide gel electrophoresis (SDS-PAGE), the phosphorylated proteins were detected using autoradiography.

The in-gel kinase assays were performed using a 10\% polyacrylaminde SDS-PAGE gel embedded with $0.1 \mathrm{mg} / \mathrm{ml}$ either $\mathrm{ABI} 1$ or $\mathrm{ABI} 2$ as a kinase substrate, as previously described (Liu X et al., 2010) and with minor modifications. The mutagenized ABI1 and $\mathrm{ABI} 2$ proteins were generated using site-directed mutagenesis methods that converted the serine residue of their kinase domains to alanine. After electrophoresis with GST, wPR5K2KD, or $\mathrm{mPR} 5 \mathrm{~K} 2 \mathrm{KD}$, the gels were washed three times with washing buffer containing $25 \mathrm{mM}$ Tris- $\mathrm{HCl}(\mathrm{pH} 7.5), 0.5 \mathrm{mM}$ dithiothreitol (DTT), $0.1 \mathrm{mM} \mathrm{Na}_{3} \mathrm{VO}_{4}, 5 \mathrm{mM} \mathrm{NaF}, 5 \%$ dried nonfat milk, and $0.1 \%$ Triton X-100. After removing the SDS, the gels were incubated at room temperature for $30 \mathrm{~min}$ in a reaction buffer containing 25 mM Tris- $\mathrm{HCl}$ (pH 7.5), 2 mM EGTA, 12 mM MgCl 2,1 mM DTT, and $0.1 \mathrm{mM} \mathrm{Na}_{3} \mathrm{VO}_{4}$. The reaction samples were combined with 250 $\mathrm{nM}$ ATP and $50 \mu \mathrm{Ci}$ of $\left[\gamma^{-32} \mathrm{P}\right]$ ATP $(3,000 \mathrm{Ci} / \mathrm{mmol})$ in the same reaction buffer, then incubated at room temperature for $1.5 \mathrm{~h}$. ABI1 and ABI2 phosphorylation were visualized using autoradiography.

\section{Bimolecular Fluorescence Complementation Assays in Tobacco Leaves}

Bimolecular fluorescence complementation (BiFC) assays were performed using Agrobacterium-infiltrated methods (Tian et al., 2011). The full-length sequences of PR5K2, ABI1, ABI2, SnRK2.6, and PYR1 were cloned into the binary gateway vectors $P D E S T$ ${ }^{G W}$ VYNE or $p D E S T-{ }^{G W}$ VYCE (Gehl et al., 2009). The N-terminal fragment (YFPVN; 1-173 a.a. of eYFP) of Venus eYFP was fused to PR5K2, while the C-terminal fragment (YFPVC; 156-239 a.a. of eYFP) was fused to the putative interaction partners used in the BiFC assay. The leaves of 4-week-old N. benthamiana plants were coinfiltrated with $A$. tumefaciens $\left(\mathrm{OD}_{600}=0.5\right)$ carrying pDEST-GWVYNE-PR5K2 (PR5K2 $\left.{ }^{V N}\right)$ and either pDEST-GWVYCE$A B I 1\left(A B I 1^{V C}\right), p D E S T-G W V Y C E-A B I 2\left(A B I 2^{V C}\right), p D E S T-{ }^{G W} V Y C E-$ SnRK2.6 (SnRK2.6 $\left.{ }^{V C}\right)$, or $p D E S T-{ }^{G W} V Y C E-P Y R 1$ (PYR1 $\left.{ }^{V C}\right)$, together with the $p 19$ plasmid, in infiltration buffer $(10 \mathrm{mM}$ MES, $10 \mathrm{mM}$ $\mathrm{MgCl}_{2}$, and $100 \mu \mathrm{M}$ acetosyringone). After 2 days of incubation, the fluorescence signals were detected using a GFP filter (excitation, 488 $\mathrm{nm}$; emission, $510 \mathrm{~nm}$ ) on a confocal laser-scanning microscope (Olympus FV1000; Olympus, Tokyo, Japan).

\section{Co-Immunoprecipitation Assays}

The full length of $A B I 1$ and $A B I 2$ cDNA was amplified from the WT using PCR and cloned into the pEarleyGate 301 gateway vector (Thermo Fisher Scientific, Waltham, MA, USA), which contained a Basta resistance gene and a $H A$ fusion sequence. The total proteins from equal amounts of $N$. benthamiana leaves expressing both PR5K2-GFP and ABI1-HA or ABI2-HA proteins were extracted in extraction buffer consisting of $100 \mathrm{mM}$ Tris- $\mathrm{HCl}$ (pH 7.5), $150 \mathrm{mM}$
$\mathrm{NaCl}, 1 \% \mathrm{NP}-40,1 \mathrm{mM}$ ethylenediaminetetraacetic acid, $3 \mathrm{mM} \mathrm{DTT}$, $2 \mathrm{mM} \mathrm{Na}_{2} \mathrm{VO}_{3}, 2 \mathrm{mM} \mathrm{NaF}, 50 \mathrm{mM} \mathrm{MG} 132$, and protease inhibitor cocktail (Roche, Basel, Switzerland). a-GFP cross-linked to protein A agarose (Thermo Fisher Scientific, Waltham, MA, USA) was added to the total protein extract and incubated for $1 \mathrm{~h}$ at $4^{\circ} \mathrm{C}$. After electrophoresis, immunoblotting was carried out using rat $a-\mathrm{HA}$ antibodies (Roche, Basel, Switzerland) and rabbit $\alpha$-GFP antibodies (Abcam, Cambridge, UK). The antigen protein was detected using chemiluminescence with the enhanced-chemiluminescencedetecting reagent (GE Healthcare, Chicago, IL, USA) and ChemiDoc ${ }^{\mathrm{TM}}$ System (Bio-Rad Laboratories, Hercules, CA, USA).

\section{RESULTS}

\section{Identification of the AtPR5K2 Receptor Kinase Involved in Drought-Stress Signaling}

The PR5Ks, which exist in both monocots and dicots, are composed of a signal peptide, and a transmembrane domain, an extracellular thaumatin-like domain, and an intracellular Ser/Thr kinase domain (Shiu and Bleecker, 2001; Liu J et al., 2010; Abdin et al., 2011; Supplementary Figure 1A). There are three Arabidopsis PR5K genes: AtPR5K1 (At5g38280), AtPR5K2 (At4g18250), and AtPR5K3 (At1g70250). The amino acid sequence of AtPR5K1 has a $55.0 \%$ similarity to AtPR5K2 and a 56.2\% similarity to AtPR5K3, while the amino acid sequence of AtPR5K2 has a 50.6\% similarity to AtPR5K3 (Supplementary Figure 1B). We analyzed expression of PR5Ks genes by Arabidopsis eFP Browser at BAR website (http:// bar.utoronto.ca/efp/cgi-bin/efpWeb.cgi). Expression patterns of $P R 5 K 1, P R 5 K 2$, and PR5K3 genes in developmental tissues were very different from each other (Supplementary Figure 2). To understand the biological function of the AtPR5Ks, we identified homozygous T-DNA insertion knockout mutants of the three AtPR5K genes, atpr5k1-1, atpr5k2-1, and atpr5k3-1, using genomic PCR and RT-PCR analyses (Supplementary Figure 3). These three atpr $k$ mutants did not show any significant phenotypic differences to the WT plants under normal growth conditions (Figure 1A and Supplementary Figure 4A).

We then tested the potential involvement of the PR5Ks with the plant responses to various abiotic stresses, including drought stress. To test their drought tolerance, water was withheld from 3-weekold WT and atpr $5 k$ mutant plants for 11 days, after which they were rewatered. After 1 day of rewatering, a drought tolerance phenotype could be observed in the atpr $5 k 2-1$ mutant plants ( $~ 81.25 \%$ survival rate) in comparison with the WT plants $(\sim 54.17 \%$ survival rate) (Figure 1A); however, the drought responses of the atpr $5 k 1-1$ and atpr5k3-1 mutants were similar to the WT plants. This suggests that AtPR5K2 plays a role in drought-stress signaling (Supplementary Figure 4). In additions, the messenger RNA expression of $R D 29 B$ in atpr5k2-1 mutant was higher than that in WT plants under drought stress condition (Supplementary Figure 5). To further confirm the role of AtPR5K2 in stress signaling, we generated AtPR5K2-overexpressing (AtPR5K2-OX) plants by introducing the full-length AtPR5K2 cDNA into the WT plant. Two independent AtPR5K2-OX lines (\#1 and \#2) with different levels of AtPR5K2 expression were selected (Supplementary Figure 6). 
A

Before

Drought

Drought

for 11d

Re-watering

for $1 d$

Survival

rate $(\%)$
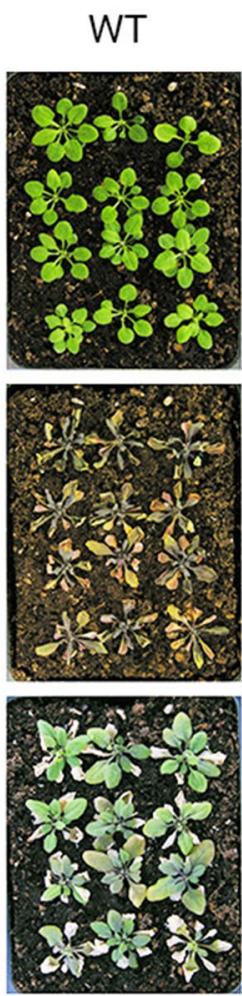

54.17

$\pm 1.29$

$$
\text { atpr5k2-1 }
$$
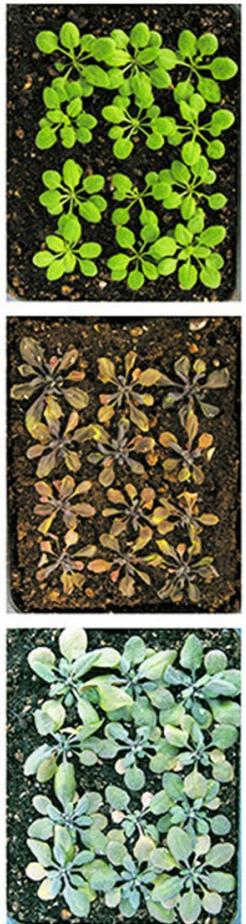

81.25

$\pm 0.5$
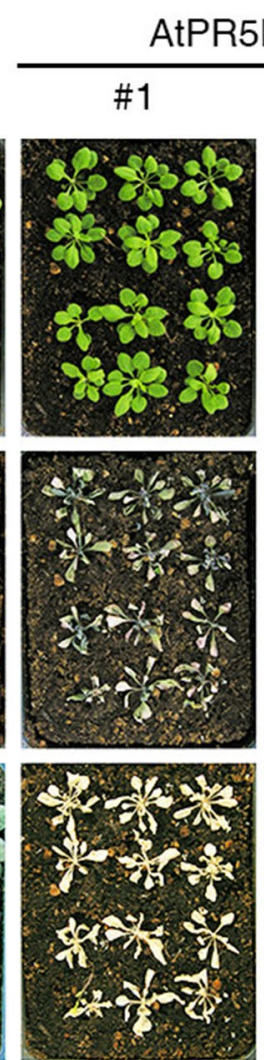

4.17

$\pm 0.58$
\#2
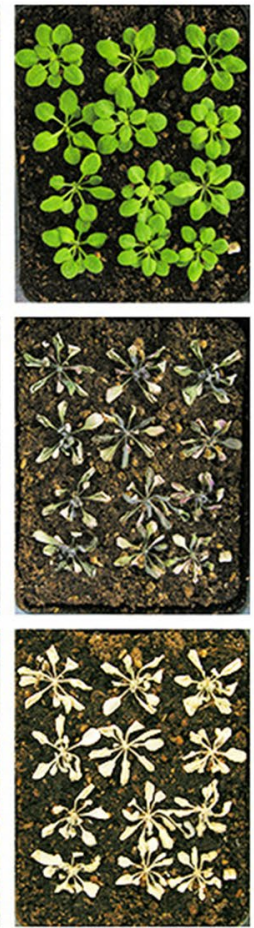

2.08

$\pm 0.5$

B

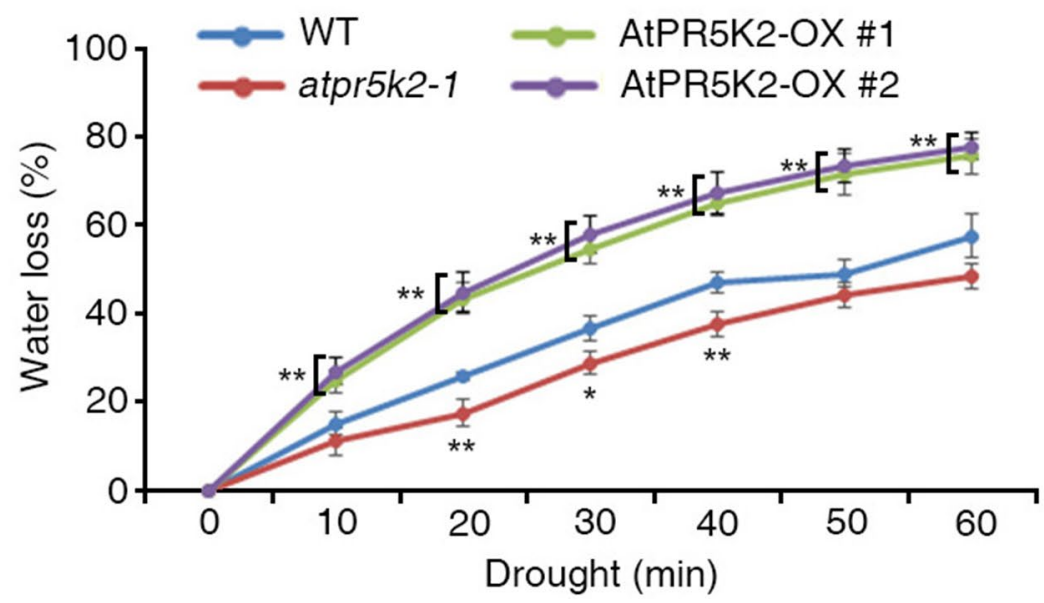

FIGURE 1 | The phenotypes of the atpr5k2-1 mutant and AtPR5K2-overexpressing (AtPR5K2-OX) plants in response to drought stress. (A) Wild type (WT), atpr5k2-1, and AtPR5K2-overexpressing plants (AtPR5K2-OX \#1 and \#2) were grown in soil with sufficient water for 3 weeks (upper row). Water was then withheld from the plants for 11 days (middle), after which the plants were rewatered for 1 day (bottom). The survival rates of the WT, atpr5k2-1, and AtPR5K2-OX \#1 and \#2 lines under drought conditions were assessed in four replicates $(n=48)$. (B) Transpirational water loss was measured in detached leaves of 4-week-old WT, atpr5k2-1, and AtPR5K2-OX \#1 and \#2 plants. The fresh weights were measured at the indicated time points, and water loss was normalized relative to a percentage of their initial fresh weight. Error bars indicate the standard deviation from three independent experiments. Asterisks represent significant differences from the WT ( ${ }^{\star} 0.01<p \leq 0.01$, Student's $t$ test). 
When subjected to 11 days of drought stress and 1 day of rewatering, the AtPR5K2-OX plants exhibited a hypersensitivity to drought response (approximately $2.08-4.17 \%$ survival rate) than the WT plants (Figure 1A).

We further examined the transpirational water loss of the WT, atpr5k2-1, and AtPR5K2-OX plants by measuring the changes in the fresh weights of detached leaves from 4-week-old plants over time. Water was lost more slowly from the atpr $5 k 2-1$ plants than from the WT, but more rapidly from the AtPR5K2-OX plants (Figure 1B). In addition, in the absence of ABA, stomatal opening in WT, atpr5k2-1, and AtPR5K2-OX plants were not different. However, in the presence of $\mathrm{ABA}$, stomatal aperture in atpr5k2-1 mutant was more significantly decreased than that in WT. The stomatal aperture of AtPR5K2-OX plants was comparable to that of WT (Supplementary Figure 7). We also tested the potential involvement of AtPR5K2 in the responses to other abiotic stresses; however, both the atpr5k2-1 mutant and the AtPR5K2-OX plants did not show any obvious phenotypic differences to WT in response to the $\mathrm{NaCl}, \mathrm{KCl}, \mathrm{LiCl}$, and mannitol stresses (Supplementary Figure 8). These results suggest that AtPR5K2 plays a role in the regulation of plant responses to drought stress specifically.

\section{AtPR5K2 Plays a Negative Role in ABA Signaling}

Water deficiency in plants has huge influences on plant growth and productivity (Bartels and Sunkar, 2005). Under water-deficient conditions, the initial plant response is to regulate the accumulation of ABA (Bartels and Sunkar, 2005). To determine whether AtPR5K2 is involved in ABA signaling, we examined the phenotypes of the atpr5k2-1 mutant and AtPR5K2-OX plants when treated with exogenous ABA. When placed on a medium containing $0.75 \mu \mathrm{M}$ ABA, the germination of the AtPR5K2-OX seeds was significantly enhanced compared with the WT, although the germination of the atpr5k2-1 seeds was not affected (Figure 2A). After germination in the presence of $0.5 \mu \mathrm{M} \mathrm{ABA}$, the atpr $5 \mathrm{k} 2-1$ mutants showed slower ( 2.7-fold) cotyledon greening than the WT; however, the cotyledon greening of the AtPR5K2-OX plants was $\sim 1.56$-fold faster than that of the WT (Figure 2B). The results indicated that AtPR5K2 functions as a negative regulator of ABA signaling during seed germination.

\section{Functional Characterization of AtPR5K2}

To study the molecular functions of AtPR5K2, we used qRT-PCR to analyze the expression pattern of AtPR5K2 in various Arabidopsis tissues, including the rosette leaves, roots, stems, cauline leaves, flowers, and siliques. We found that AtPR5K2 is highly expressed in the rosette and cauline leaves (Figure 3A). Furthermore, the messenger RNA level of AtPR5K2 was dramatically induced in response to drought stress (Supplementary Figure 9). To examine the subcellular localization of the AtPR5K2 protein, the full-length AtPR5K2 cDNA was fused with GFP and expressed under the control of CaMV $35 S$ promoter. Aquaporin fused with red fluorescent protein was used as a plasma-membrane marker. 35S:AtPR5K2-GFP and 35S:Aquaporin-RFP were transiently coexpressed in Arabidopsis protoplasts, and the GFP signal was

A

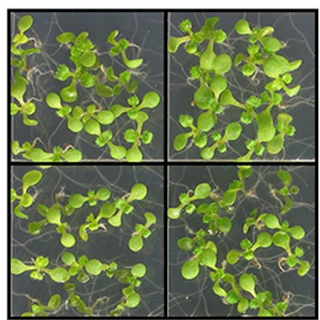

$0 \mu \mathrm{M} A B A$

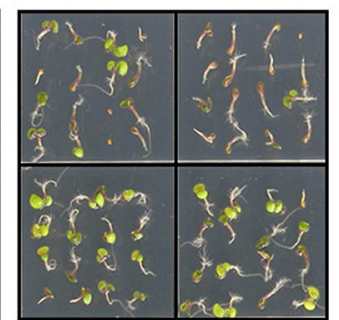

$0.75 \mu \mathrm{M} \mathrm{ABA}$

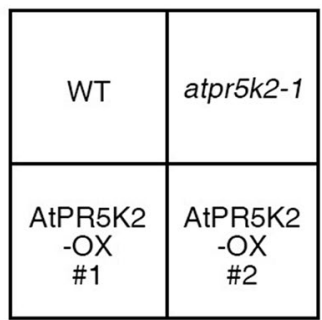

AtPR5K2-OX \#1 AtPR5K2-OX \#2

B

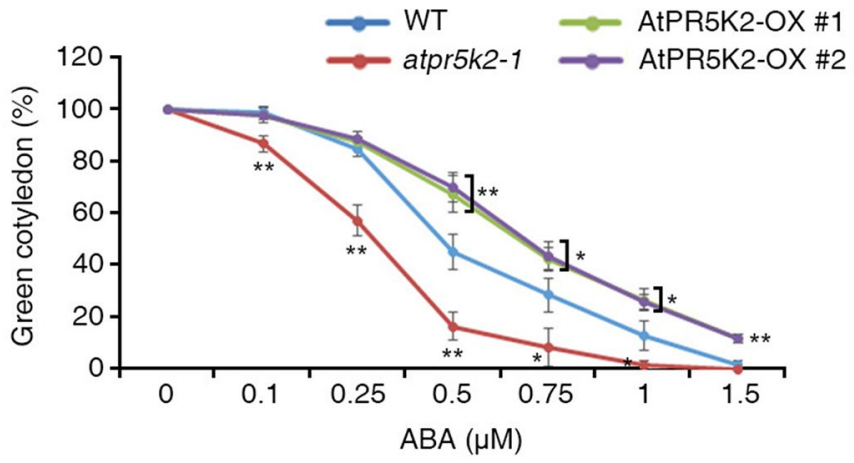

FIGURE 2 | The phenotypes of the atpr5k2-1 mutant and AtPR5K2-overexpressing (AtPR5K2-OX) plants in response to ABA stress. (A) WT, atpr5k2-1, and AtPR5K2-OX \#1 and \#2 plants were germinated on 1/2 Murashige and Skoog (MS) with and without $0.75 \mu \mathrm{M}$ abscisic acid (ABA) for 5 days. The ABA sensitivity analysis was performed in triplicate by using at least 50 seeds from each line in each experiment. (B) The cotyledon greening of WT, atpr5k2-1, and AtPR5K2-OX \#1 and \#2 seedlings germinated on 1/2 MS containing different concentrations of ABA for 5 days. Cotyledon greening was determined as a percentage of the seeds plated $(n=50)$. Error bars indicate the standard deviation from three independent experiments. Asterisks represent significant differences from the WT ( ${ }^{*} 0.01<p \leq 0.01$, Student's $t$ test). 
observed to overlap with the plasma-membrane signal, suggesting that the protein is localized to the plasma membrane (Figure 3B). To confirm its plasma membrane localization, we induced plasmolysis in tobacco epidermal cells expressing AtPR5K2-GFP. The GFP fluorescence was still observed at clear separation of the plant protoplast from the cell wall organizing Hechtian strands, which was interrelated cell wall and plasma membrane after plasmolysis (Figure 3C). These data indicated that AtPR5K2 was localized to the plasma membrane.

One of the AtPR5Ks, AtPR5K1, was previously been shown to have autocatalytic kinase activity in vitro (Wang et al., 1996). To determine whether AtPR5K2 has autophosphorylation activity, we fused the protein kinase domain-encoding sequence of AtPR5K2
(wPR5K2KD) with GST and expressed it in E. coli. The purified recombinant $\mathrm{wPR} 5 \mathrm{~K} 2 \mathrm{KD}$ proteins were reacted with radioactive $\left[\gamma^{-}{ }^{32} \mathrm{P}\right]$ ATP and separated using SDS-PAGE. A phosphorylated band was detected on the resulting gel at the position approximating a molecular weight of $65 \mathrm{kDa}$, which corresponded to the molecular weight of the recombinant wPR5K2KD protein (Figure 3D). To impede the kinase activity of AtPR5K2, we substituted the lysine residue (amino acid position 352) in the kinase domain with arginine. This lysine residue is known to be important for ATP binding in many kinases (Carrera et al., 1993). The kinase activity of the mPR5K2KD protein was significantly reduced compared with that of wPR5K2KD (Figure 3D), indicating that AtPR5K2 has a functional kinase activity.

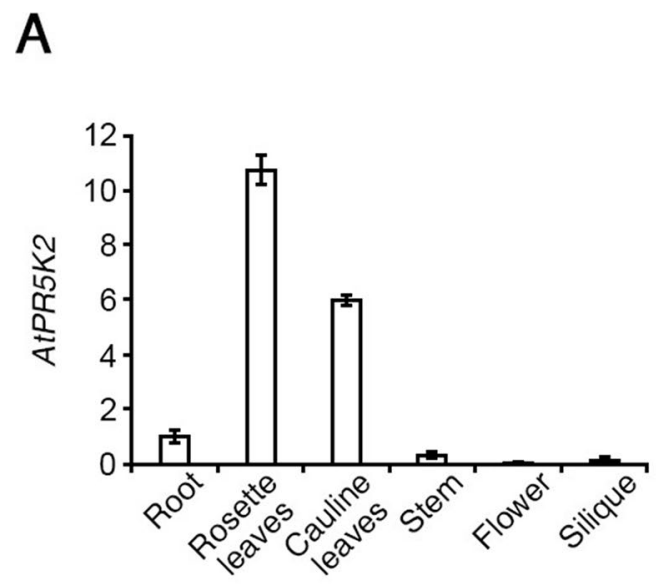

B
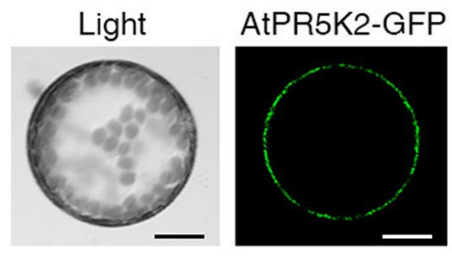

Aquaporin-RFP
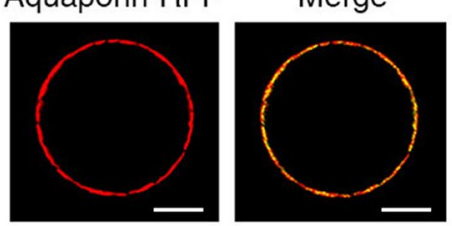

C

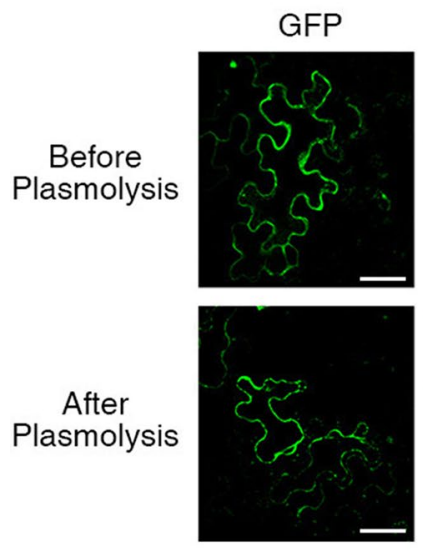

Light/GFP
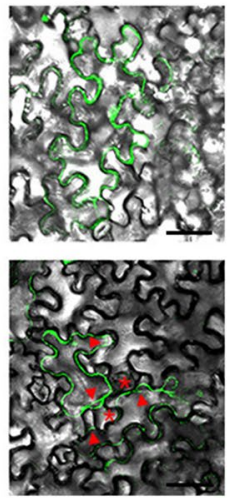

D

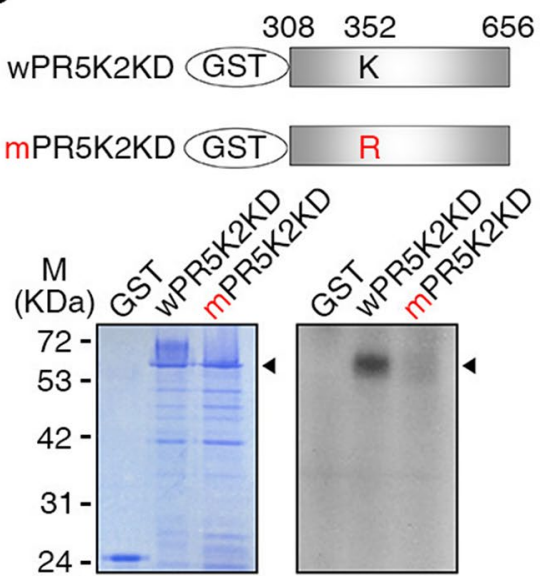

FIGURE 3 | Expression patterns and subcellular localization of AtPR5K2. (A) The expression of AtPR5K2 in various tissues of Arabidopsis thaliana. Total RNA was extracted from the roots, rosette leaves, cauline leaves, stems, flowers, and siliques of the wild-type plants. The transcript levels of AtPR5K2 were measured using quantitative reverse transcription PCR (qRT-PCR) and calculated relative to the expression of the endogenous control gene, TUBULIN2. Error bars represent the \pm SD from three independent experiments. (B) Subcellular localization of AtPR5K2 in Arabidopsis protoplasts. 35S:AtPR5K2-GFP and Aquaporin-RFP were coexpressed in Arabidopsis protoplasts, which were analyzed using confocal fluorescence microscopy and photographed after $24 \mathrm{~h}$ of incubation at $22^{\circ} \mathrm{C}$. Aquaporin-RFP is a plasma-membrane marker. Scale bars represent $10 \mu \mathrm{m}$. (C) Subcellular localization of AtPR5K2 in the epidermal cells of tobacco (Nicotiana benthamiana) leave expressing 35S:AtPR5K2-GFP before and after plasmolysis. The epidermal cells were analyzed using confocal fluorescence microscopy and photographed after 48 $\mathrm{h}$ of incubation at $25^{\circ} \mathrm{C}$. Scale bars represent $20 \mu \mathrm{m}$. Red asterisk indicates that AtPR5K2-GFP signal remains in the Hechtian strands. Red arrowheads point to the retracted plasma membrane. (D) In vitro kinase assays of AtPR5K2. The upper panel indicates the schematic structure of the GST-fused AtPR5K2 kinase domain (wPR5K2KD) and the GST-fused mutagenized AtPR5K2 kinase domain (mPR5K2KD). Each kinase domain was individually expressed in Escherichia coli, and $2 \mu \mathrm{g}$ purified proteins was incubated in kinase assay buffer. Radioactive-labeled products were separated on sodium dodecyl sulfate polyacrylamide gel electrophoresis (SDS-PAGE) gels and detected using radioactivity (bottom right). After electrophoresis, the purified products were stained with Coomassie brilliant blue (bottom left). 


\section{AtPR5K2 Interacts With Protein Phosphatase 2C and SnRK2.6 in the ABA Signaling Pathway}

The core components of the ABA signalosome, including the PYR/ PYL/RCAR ABA receptors, $\mathrm{PP} 2 \mathrm{Cs}$, and $\mathrm{SnRK} 2$ s, play a major role in the ABA signal transduction and plant adaptive responses to environmental stresses (Ma et al., 2009; Melcher et al., 2009). The PP2Cs, ABI1 and ABI2, act as negative regulators of ABA signaling (Kuhn et al., 2006; Saez et al., 2006), while SnRK2.6/OST1 acts as a positive regulator of ABA-dependent stomatal closure (Yoshida et al., 2006a; Kulik et al., 2011). To test whether AtPR5K2 is involved in ABA signalosome-mediated signaling, we tested the in vivo interaction between AtPR5K2 and the PP2Cs using BiFC assays. The full-length AtPR5K2 cDNA sequence was fused to the N-terminal fragment of the Venus protein (AtPR5K2 ${ }^{\mathrm{VN}}$ ), while $\mathrm{ABI} 1$ or $\mathrm{ABI} 2$ was fused to the C-terminal fragment of Venus $\left(\mathrm{ABI} 1^{\mathrm{VC}}\right.$ or $\mathrm{ABI} 2^{\mathrm{VC}}$, respectively). Fluorescence signals were detected in the plasma membrane of the tobacco epidermal cells when AtPR5K2 $2^{\mathrm{VN}}$ was coexpressed with $\mathrm{ABI} 1^{\mathrm{VC}}$ or $\mathrm{ABI} 2^{\mathrm{VC}}$ (Figure 4A), while no fluorescence signals were detected when these constructs were coexpressed with the empty YFPVC or $\mathrm{YFP}^{\mathrm{VN}}$ vectors (Supplementary Figure 10). To further confirm the interaction of AtPR5K2 with ABI1 or ABI2, we conducted in vivo coimmunoprecipitation assays in tobacco leaves. The fulllength AtPR5K2 sequence was fused to GFP (AtPR5K2-GFP), while $\mathrm{ABI} 1$ and $\mathrm{ABI} 2$ were individually fused to the $\mathrm{HA}$ tag protein (ABI1-HA or ABI2-HA). The total proteins of tobacco leave coinfiltrated AtPR5K2-GFP and ABI1-HA or ABI2-HA were immunoprecipitated with an $\alpha$-GFP antibody, and the eluted precipitates were detected using an $\alpha-\mathrm{HA}$ antibody, revealing that AtPR5K2 interacts with $\mathrm{ABI} 1$ and $\mathrm{ABI} 2$ in vivo (Figure 4B).

The physical interaction of the PP2Cs with the PYLs or SnRK2s was previously identified during ABA signaling (Yoshida et al., 2006a; Park et al., 2009; Nishimura et al., 2010). To test interaction between AtPR5K2 and SnRK2.6 or PYL1, we performed BiFC assays using SnRK2.6 or PYL1 fused to the C-terminal fragment of Venus (SnRK2.6 $6^{\mathrm{VC}}$ and PYL1 ${ }^{\mathrm{VC}}$, respectively). Fluorescence signals were detected in the plasma membrane of the epidermal cells coexpressing AtPR5K2 $2^{V N}$ and $S n R K 2.6^{V C}$ (Figure 4C); however, no interaction was detected between AtPR5K2 $2^{\mathrm{VN}}$ and PYL1 $^{\mathrm{VC}}$ (Figure 4D). Taken together, these results suggest that AtPR5K2 plays an important role in the regulation of ABA core signaling by interacting with the PP2Cs and SnRK2.6.

\section{ABA Affects the Interactions of AtPR5K2 With the PP2Cs and SnRK2.6}

In the absence of ABA, the PP2Cs inhibit the autophosphorylation and activation of SnRK2.6 in ABA core signaling, while intracellular $\mathrm{ABA}$ enhances the in vivo interaction between the PP2Cs and PYL receptors (Nishimura et al., 2010). Thus, in the presence of ABA, the inhibitory effect of the PP2Cs on SnRK2.6 is removed, activating SnRK2.6 to phosphorylate ion channels or AREB/ABF transcription factors to stimulate the ABA response (Yoshida et al., 2006a; Yoshida et al., 2010). To investigate whether elevated cellular ABA levels affect the interaction of AtPR5K2 with the PP2Cs or SnRK2.6, we performed the BiFC assays in the presence and absence of exogenous ABA, by coexpressing AtPR5K2 ${ }^{\mathrm{VN}}$ with $\mathrm{ABI} 1^{\mathrm{VC}}, \mathrm{ABI} 2^{\mathrm{VC}}$, or $\mathrm{SnRK} 2.6^{\mathrm{VC}}$ in tobacco cells. The fluorescence signals in the tobacco leaves coexpressing AtPR5K2 $2^{\mathrm{VN}} / \mathrm{ABI} 1^{\mathrm{VC}}$, AtPR5K2 $2^{\mathrm{VN}} / \mathrm{ABI} 2^{\mathrm{VC}}$, and AtPR5K2 $2^{\mathrm{VN}} / \mathrm{SnRK} 2.6^{\mathrm{VC}}$ were weaker in the presence of $10 \mu \mathrm{M}$ exogenous ABA conditions than in the absence of ABA (Figure 5), suggesting that elevated ABA levels disrupt the interaction of AtPR5K2 with ABI1, ABI2, and SnRK2.6.

\section{AtPR5K2 Phosphorylates the PP2Cs $A B \mid 1$ and $A B I 2$}

To investigate whether AtPR5K2 could specifically phosphorylate ABI1, ABI2, or SnRK2.6, we performed in-gel kinase assays to test the phosphorylation of ABI1-GST, ABI2-GST, and SnRK2.6GST by AtPR5K2. The kinase domain of PR5K2 (wPR5K2KD) phosphorylated ABI1 and ABI2 (Figure 6); however, no phosphorylation was detected when SnRK2.6 or GST were used as substrates (Figure 6 and Supplementary Figure 11). In addition, the phosphorylation of ABI1 and ABI2 was strongly attenuated by the mutation of the PR5K kinase domain (mPR5K2KD; Figure 6).

To further confirm that ABI1 and ABI2 function as substrates for AtPR5K2, we investigated the putative phosphorylation site of $\mathrm{ABI} 1$ and $\mathrm{ABI} 2$ by analyzing the amino acid sequences the of PP2Cs using the Plant Protein Phosphorylation DataBase (http://www. p3db.org). The putative phosphorylation sites in ABI1 (Ser-314) and ABI2 (Ser-304) were substituted with alanine (ABI1 ${ }^{\mathrm{S} 314 \mathrm{~A}}$ and $\mathrm{ABI} 2^{\mathrm{S} 304 \mathrm{~A}}$, respectively; Han et al., 2018). We performed in-gel kinase assays using $\mathrm{ABI}{ }^{\mathrm{S} 314 \mathrm{~A}}$ and $\mathrm{ABI} 2^{\mathrm{S} 304 \mathrm{~A}}$ as substrates for the AtPR5K2 kinase domain (Figure 6), revealing that their phosphorylation by wPR5K2KD was greatly attenuated in comparison with the WT $\mathrm{ABI} 1$ and $\mathrm{ABI} 2$ proteins (Figure 6). These results suggested that AtPR5K2 phosphorylates the ABI1 and ABI2 phosphatases to modulate their activities during ABA core signaling.

\section{DISCUSSION}

\section{AtPR5K2 Negatively Regulates ABA Signaling}

Several RLKs are known to function in abiotic stress signaling (Osakabe et al., 2005; Bai et al., 2009; Tanaka et al., 2012; Kumar et al., 2017). Some RLKs are involved in ABA signaling; however, the mechanisms by which they interact with the ABA core signaling pathway were not previously understood. AtRPK1 expression is rapidly induced by various abiotic stresses, such as ABA, drought, salinity, and cold, indicating that RPK1 mediates abiotic stress responses (Hong et al., 1997), while proline-rich extensin-like receptor kinase 4, an $\mathrm{ABA}$ - and $\mathrm{Ca}^{2+}$-activated protein kinase, was functionally characterized in the initial stages of ABA signaling (Bai et al., 2009). A cysteine-rich repeat RLK36negatively regulates $\mathrm{ABA}$ and osmotic stress signaling by interacting with receptor-like cytosolic kinase 1 (Tanaka et al., 2012). BRI1-associated receptor kinase 1 interacts with SnRK2.6 to induce stomatal closure in response to $\mathrm{ABA}$, in contrast with the function of $\mathrm{ABI} 1$ during the ABA responses (Shang et al., 2016). Receptor dead kinase 1 is a positive regulator of ABA-dependent abiotic-stress signaling (Kumar et al., 2017). In the present study, we characterized the role of AtPR5K2 in ABA-dependent drought-stress signaling. It was 


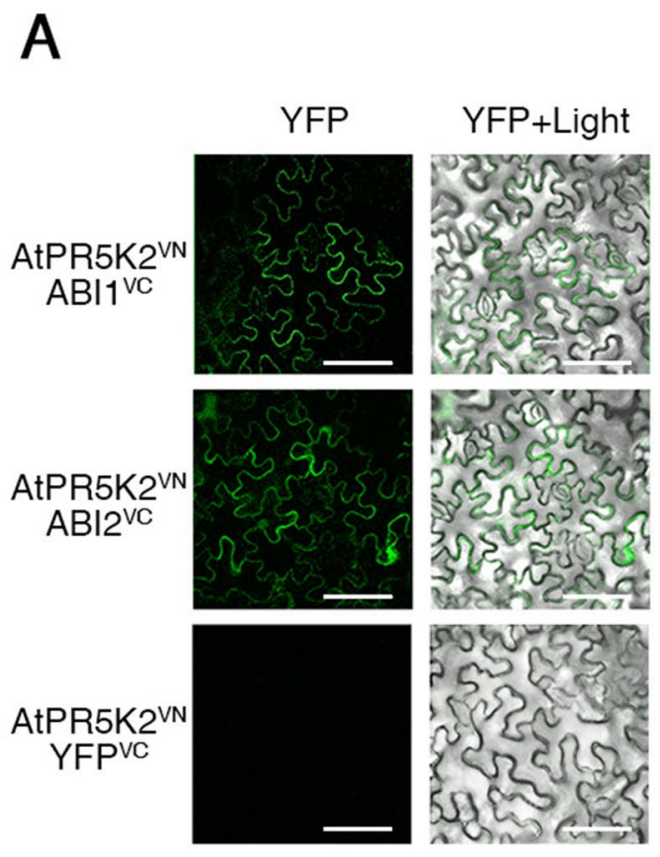

B
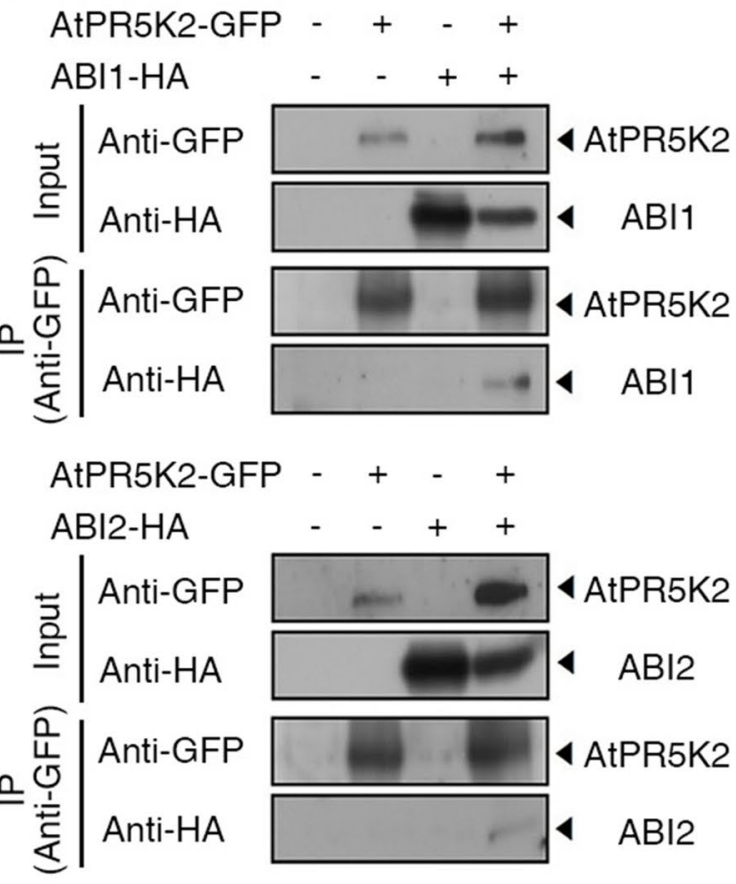

C
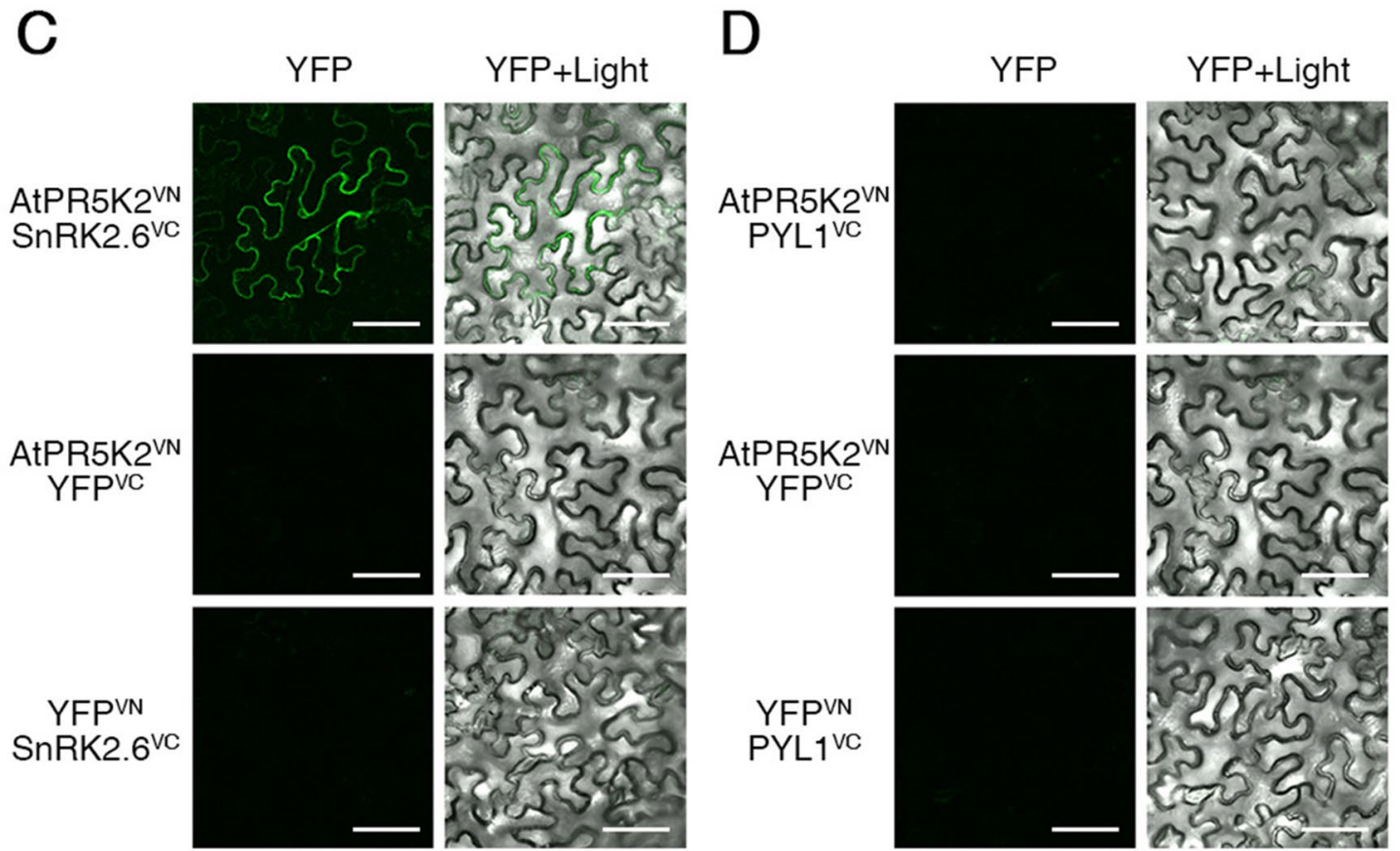

FIGURE 4 | AtPR5K2 interaction with ABI1, ABI2, and SnRK2.6 in vivo and in vitro. (A) Bimolecular fluorescence complementation (BiFC) analysis of AtPR5K2 and PP2Cs coexpressed in tobacco (Nicotiana benthamiana) leaves. VN and VC indicate the $\mathrm{N}$ - and C-terminal regions of Venus (eYFP), respectively. The epidermal cells were analyzed using confocal fluorescence microscopy and photographed after $48 \mathrm{~h}$ of incubation at $25^{\circ} \mathrm{C}$. Scale bars represent $100 \mathrm{\mu m}$. (B) AtPR5K2 forms a complex with the PP2Cs. Each combination of 35S:AtPR5K2-GFP, 35S:AB/1-HA, and 35S:ABI2-HA were transiently expressed in tobacco plants. The proteins were immunoprecipitated with an alpha-green fluorescent protein ( $\alpha$-GFP) antibody and resolved with SDS-PAGE. The immunoblots were probed with an $\alpha$-GFP antibody to detect AtPR5K2 or an a-HA antibody to detect ABI1 and ABI2. The minus (-) indicated empty vectors (35S:GFP or 35S:HA, respectively) as negative controls. (C and D) BiFC analysis of AtPR5K2 and SnRK2.6 (C) or PYL1 (D) coexpressed in tobacco leaves. The epidermal cells were analyzed using confocal fluorescence microscopy and photographed after $48 \mathrm{~h}$ of incubation at $25^{\circ} \mathrm{C}$. Scale bars represent $100 \mu \mathrm{m}$. 


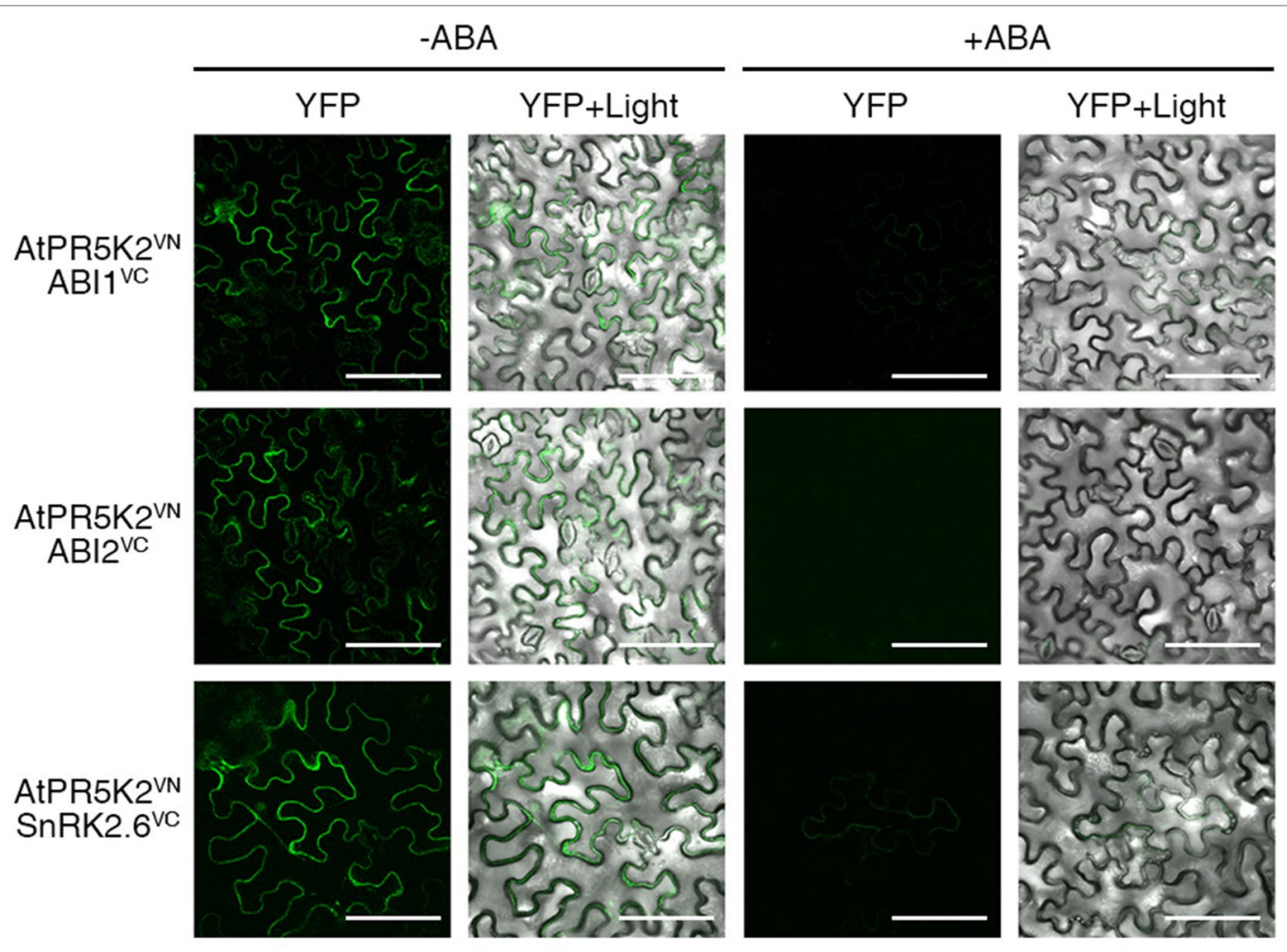

FIGURE 5 | Influence of the AtPR5K2 complex on ABA stress signaling. BiFC analysis of AtPR5K2 and ABI1, ABI2, or SnRK2.6 transiently coexpressed in tobacco (Nicotiana benthamiana) leaves in the presence of absence of $10 \mu \mathrm{M}$ exogenous $\mathrm{ABA}$. VN and VC indicate the N- and C-terminal regions of Venus (eYFP), respectively. The epidermal cells were analyzed using confocal fluorescence microscopy and photographed after $48 \mathrm{~h}$ of incubation at $25^{\circ} \mathrm{C}$ in the presence or absence of ABA. Scale bars represent $100 \mu \mathrm{m}$
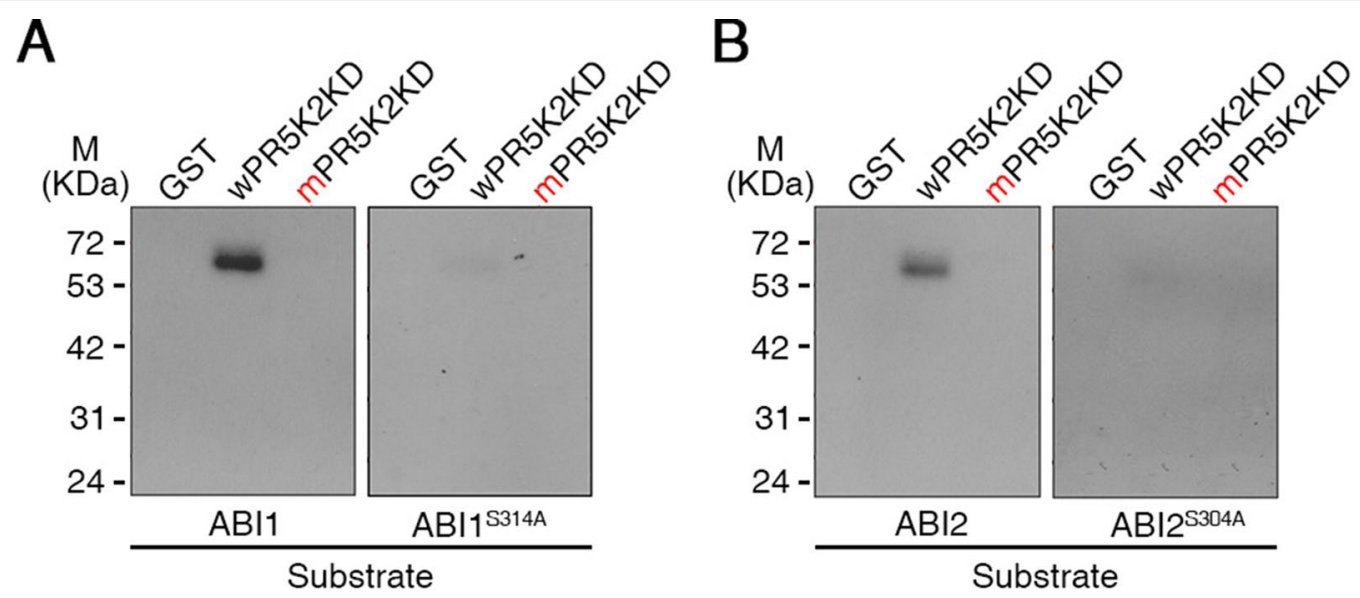

FIGURE 6 | In-gel kinase assay of AtPR5K2. The recombinant fusion protein of the AtPR5K2 kinase domain (wPR5K2KD) or the mutagenized AtPR5K2 kinase domain (mPR5K2KD) was denatured and separated on an SDS gel. An in-gel kinase assay was performed using recombinant ABI1 (A; left), ABI1 S314A (A; right), $\mathrm{ABI} 2$ (B; left), or $\mathrm{ABI}{ }^{\mathrm{S} 304 \mathrm{~A}}$ (B; right) as an embedded substrate. The GST tag served as a negative control.

found to interact with $\mathrm{ABI} 1$ and $\mathrm{ABI} 2$ on the plasma membrane (Figure 4) and phosphorylate them in vitro (Figures 3 and 6). ABI1 and $\mathrm{ABI} 2$ are typical $\mathrm{PP} 2 \mathrm{C}$ proteins and key negative regulators of the ABA core signaling pathway (Cutler et al., 2010; Raghavendra et al., 2010). In addition, the AtPR5K2-OX plants underwent significantly higher levels of cotyledon greening than the WT when treated with ABA (Figure 2). These findings suggested that AtPR5K2 could act as a negative regulator of ABA signaling that modulates the functions of the PP2Cs.

Age-dependent leaf senescence is associated with various environmental stresses and changes of various plant hormones, such as ABA (Lim et al., 2007). It is recently reported that drought 
tolerance is enhanced when drought-induced leaf senescence is delayed in plants (Rivero et al., 2007). Arabidopsis RPK1, receptor protein kinase 1 , mediates ABA-induced and agedependent leaf senescence (Lee et al., 2011). The ABA receptor PYL9 improved ability of drought resistance as well as ABAinduced leaf senescence (Zhao et al., 2016). These results suggest the crosstalk between ABA-dependent drought stress signaling and leaf senescence. Based on these observations, it would be possible that AtPR5K2 may play a role in cross-talk between ABA-dependent drought stress signaling and leaf senescence. We intend to test the role of AtPR5K2 in drought- and ABAmediated leaf senescence in the future study.

\section{AtPR5K2 Directly Phosphorylates the PP2Cs But Not SnRK2.6 in the ABA Signalosome}

Although AtPR5K1 was previously reported to have kinase activity (Wang et al., 1996), the function of the closely related AtPR5K2 protein was not previously known. AtPR5K2 comprises a thaumatin-like domain, a transmembrane domain, and a Ser/ Thr kinase domain, the latter of which showed high similarity with that of AtPR5K1 (Supplementary Figure 1). Like AtPR5K1, AtPR5K2 has an efficient kinase activity which requires the lysine residue in its kinase domain (Figure 3D).

We investigated several major components of the ABA core signaling pathway as potential target substrates for AtPR5K2. ABI1, ABI2, and SnRK2.6 were previously known to be activated by phosphorylation during the ABA response (Kulik et al., 2011; Ma et al., 2009; Umezawa et al., 2009b; Ng et al., 2011); however, the mechanisms of this phosphorylation remained unclear. We showed that AtPR5K2 phosphorylated ABI1 and ABI2 in vitro (Figure 6), but did not use SnRK2.6 as a substrate (Supplementary Figure 11). In addition, we identified the putative phosphorylation sites of ABI1 (Ser-314) and ABI2 (Ser-304) used by AtPR5K2 (Figure 6). To our knowledge, AtPR5K2 is the first plant novel receptor kinase known to phosphorylate $\mathrm{ABI} 1$ and $\mathrm{ABI} 2$.

\section{Proposed Working Model of AtPR5K2 in ABA Core Signaling}

The ABA-mediated signal transduction pathway has been extensively studied, and many of its regulators have been elucidated (Finkelstein et al., 2002; Cutler et al., 2010; Raghavendra et al., 2010). Here, we added a new key component, AtPR5K2, to the ABA core signaling pathway (Figure 7). In the absence of ABA, AtPR5K2 interacts with the PP2Cs and SnRK2.6, but not with PYL1 ABA receptor. Active AtPR5K2 phosphorylates PP2C phosphatases, such as ABI1 and ABI2, which inhibit the activity of SnRK2.6, a positive regulator of ABA signaling, via dephosphorylation. This means that, in the absence of ABA, AtPR5K interrupts the ABA signal transduction and the expression of the ABA-dependent genes. Under stress conditions, such as drought, increased intracellular ABA dissociates the PP2Cs and SnRK2.6 from AtPR5K2 (Figure 5 and Figure 7). The released PP2Cs directly bind to both ABA and the PYL receptors and become inactivated. Subsequently, the SnRK2.6 kinase is activated by autophosphorylation and phosphorylates the $\mathrm{ABRE} / \mathrm{ABF}$ transcription factors to induce the expression of ABA-dependent genes, which enhances plant tolerance to various abiotic stresses (Figure 7).
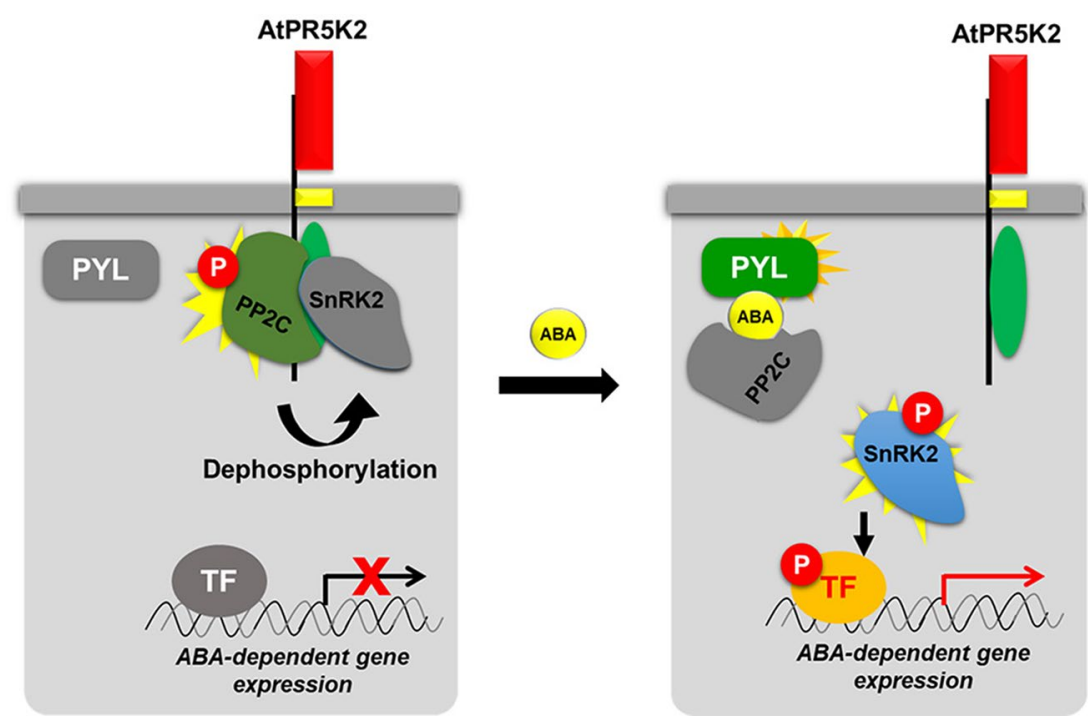

FIGURE 7 | Proposed working model of AtPR5K2 in ABA core signaling. AtPR5K2 is single transmembrane protein with an N-terminal thaumatin-like domain (red box), a single transmembrane domain (yellow box), and a C-terminal Ser/Thr kinase domain (green oval). In the absence of ABA, the phosphatase activity of the PP2Cs is enhanced by AtPR5K2-dependent phosphorylation. The activated PP2Cs dephosphorylate the SnRK2s, decreasing their activity. Thus, the ABAdependent gene expression regulated by SnRK2 is attenuated. In the presence of ABA, the protein-protein interaction affinities among AtPR5K2, PP2Cs, and SnRK2s are weakened. This means that the PP2Cs and SnRK2 are released from AtPR5K2, freeing SnRK2.6 to autophosphorylate itself and phosphorylate the transcription factors regulating ABA-dependent gene expression. In the case of the PP2Cs and SnRK2.6, a vivid coloration indicates an active status, while the gray color indicates an inactive status. The red circle containing the letter "P" indicates phosphorylation. 


\section{CONCLUSION}

We identified and characterized the role of AtPR5K2, a PR5like receptor kinase, in ABA core signaling during plant responses to drought stress. The AtPR5K2-OX plants were hypersensitive to drought stress and tolerant of exogenous ABA, suggesting that AtPR5K2 mediates ABA-dependent drought-stress signaling. Our molecular and biochemical results suggest that, under normal growth conditions, AtPR5K2 probably deactivates ABA core signaling and ABA-dependent gene expression by modulating the phosphorylation status of the PP2Cs and SnRK2.6, a major factor in stomatal closure. In response to abiotic stresses, however, AtPR5K2 turns on the ABA core signaling cascade and $\mathrm{ABA}$-dependent gene expression by releasing the PP2Cs and freeing SnRK2.6 to promote ABA signaling. Our results demonstrate that AtPR5K2 plays an important role as a key negative regulator of $\mathrm{ABA}$ core signaling by phosphorylating the PP2C phosphatases, such as ABI1 and ABI2.

\section{DATA AVAILABILITY STATEMENT}

All datasets for this study are included in the manuscript and the Supplementary Files.

\section{REFERENCES}

Abdin, M. Z., Kiran, U., and Alam, A. (2011). Analysis of osmotin, a PR protein as metabolic modulator in plants. Bioinformation 5 (8), 336-340. doi: 10.6026/97320630005336

Baek, D., Kim, M. C., Chun, H. J., Kang, S., Park, H. C., Shin, G., et al. (2013). Regulation of miR399f transcription by AtMYB2 affects phosphate starvation responses in Arabidopsis. Plant Physiol. 161 (1), 362-373. doi: 10.1104/ pp.112.205922

Bai, L., Zhang, G., Zhou, Y., Zhang, Z., Wang, W., Du, Y., et al. (2009). Plasma membrane-associated proline-rich extensin-like receptor kinase 4, a novel regulator of Ca signalling, is required for abscisic acid responses in Arabidopsis thaliana. Plant J. 60 (2), 314-327. doi: 10.1111/j.1365-313X.2009.03956.x

Bartels, D., and Sunkar, R. (2005). Drought and Salt Tolerance. Plants. Crit. Rev. Plant Sci. 24 (1), 23-58.

Becraft, P. W., Stinard, P. S., and McCarty, D. R. (1996). CRINKLY4: a TNFR-like receptor kinase involved in maize epidermal differentiation. Science 273 (5280), 1406-1409. doi: 10.1126/science.273.5280.1406

Carrera, A. C., Alexandrov, K., and Roberts, T. M. (1993). The conserved lysine of the catalytic domain of protein kinases is actively involved in the phosphotransfer reaction and not required for anchoring ATP. Proc. Natl. Acad. Sci. U.S.A. 90 (2), 442-446. doi: 10.1073/pnas.90.2.442

Clark, S. E., Williams, R. W., and Meyerowitz, E. M. (1997). The CLAVATA1 gene encodes a putative receptor kinase that controls shoot and floral meristem size in Arabidopsis. Cell 89 (4), 575-585. doi: 10.1016/S0092-8674(00)80239-1

Clarke, J. D., Volko, S. M., Ledford, H., Ausubel, F. M., and Dong, X. (2000). Roles of salicylic acid, jasmonic acid, and ethylene in CPR-induced resistance in Arabidopsis. Plant Cell 12 (11), 2175-2190. doi: 10.1105/tpc.12.11.2175

Clough, S. J., and Bent, A. F. (1998). Floral dip: a simplified method for Agrobacterium-mediated transformation of Arabidopsis thaliana. Plant J. 16 (6), 735-743. doi: 10.1046/j.1365-313x.1998.00343.x

Cutler, S. R., Rodriguez, P. L., Finkelstein, R. R., and Abrams, S. R. (2010). Abscisic acid: emergence of a core signaling network. Annu. Rev. Plant Biol. 61, 651-679. doi: 10.1146/annurev-arplant-042809-112122

\section{AUTHOR CONTRIBUTIONS}

$\mathrm{DB}, \mathrm{MK}, \mathrm{J}-\mathrm{YK}$, and D-JY designed the experiments. DB and DK performed most of the experiments, and MK, J-YK, and D-JY wrote the manuscript. HC, SL, and RB discussed and commented on the results and manuscripts. BP, MC, WC, HCP, and HJP performed some of the experiments. D-JY, J-YK, MK, and DB provided funding for research work.

\section{FUNDING}

This work was supported by the Next Generation BioGreen21 Program [SSAC, grant number PJ01318201 (to D-JY) and PJ01318202 (to MCK)], the Rural Development Administration Republic of Korea, and the Basic Science Research Program through the National Research Foundation of Korea (NRF) funded by the Ministry of Education [2015R1A6A1A03031413 (to MCK), NRF2017R1A4A1015515 (to J-YK), 2016R1D1A1B01011803 (to DB), and Global Resea rch Laboratory 2017K1A1A2013146 (to D-JY)].

\section{SUPPLEMENTARY MATERIAL}

The Supplementary Material for this article can be found online at: https://www.frontiersin.org/articles/10.3389/fpls.2019.01146/ full\#supplementary-material

Durrant, W. E., and Dong, X. (2004). Systemic acquired resistance. Annu. Rev. Phytopathol. 42, 185-209. doi: 10.1146/annurev.phyto.42.040803.140421

Finkelstein, R. R., Gampala, S. S., and Rock, C. D. (2002). Abscisic acid signaling in seeds and seedlings. Plant Cell 14 (Suppl), S15-S45. doi: 10.1105/tpc.010441

Fujii, H., and Zhu, J. K. (2009b). Arabidopsis mutant deficient in 3 abscisic acid-activated protein kinases reveals critical roles in growth, reproduction, and stress. Proc. Natl. Acad. Sci. U.S.A. 106 (20), 8380-8385. doi: 10.1073/ pnas.0903144106

Fujii, H., Chinnusamy, V., Rodrigues, A., Rubio, S., Antoni, R., Park, S. Y., et al. (2009a). In vitro reconstitution of an abscisic acid signalling pathway. Nature 462 (7273), 660-664. doi: 10.1038/nature08599

Gehl, C., Waadt, R., Kudla, J., Mendel, R. R., and Hänsch, R. (2009). New GATEWAY vectors for high throughput analyses of protein-protein interactions by bimolecular fluorescence complementation. Mol. Plant 2 (5), 1051-1058. doi: $10.1093 / \mathrm{mp} / \mathrm{ssp} 040$

Gonzalez-Guzman, M., Pizzio, G. A., Antoni, R., Vera-Sirera, F., Merilo, E., Bassel, G. W., et al. (2012). Arabidopsis PYR/PYL/RCAR receptors play a major role in quantitative regulation of stomatal aperture and transcriptional response to abscisic acid. Plant Cell 24 (6), 2483-2496. doi: 10.1105/tpc.112.098574

Han, T., Zhan, W., Gan, M., Liu, F., Yu, B., Chin, Y. E., et al. (2018). Phosphorylation of glutaminase by $\mathrm{PKC} \varepsilon$ is essential for its enzymatic activity and critically contributes to tumorigenesis. Cell Res. 28 (6), 655-669. doi: 10.1038/ s41422-018-0021-y

Hatakeyama, K., Takasaki, T., Suzuki, G., Nishio, T., Watanabe, M., Isogai, A., et al. (2001). The S receptor kinase gene determines dominance relationships in stigma expression of self-incompatibility in Brassica. Plant J. 26 (1), 69-76. doi: 10.1046/j.1365-313x.2001.01009.x

Hohmann, U., Lau, K., and Hothorn, M. (2017). The structural basis of ligand perception and signal activation by receptor kinases. Annu. Rev. Plant Biol. 68, 109-137. doi: 10.1146/annurev-arplant-042916-040957

Hong, S. W., Jon, J. H., Kwak, J. M., and Nam, H. G. (1997). Identification of a receptor-like protein kinase gene rapidly induced by abscisic acid, dehydration, high salt, and cold treatments in Arabidopsis thaliana. Plant Physiol. 113 (4), 1203-1212. doi: 10.1104/pp.113.4.1203 
Hou, X., Tong, H., Selby, J., Dewitt, J., Peng, X., and He, Z. H. (2005). Involvement of a cell wall-associated kinase, WAKL4, in Arabidopsis mineral responses. Plant Physiol. 139 (4), 1704-1716. doi: 10.1104/pp.105.066910

Jin, P., Guo, T., and Becraft, P. W. (2000). The maize CR4 receptor-like kinase mediates a growth factor-like differentiation response. Genesis 27, 104-116. doi: 10.1002/1526-968X(200007)27:3<104::AID-GENE30>3.0.CO;2-I

Kang, S.-G., Lee, H. J., and Suh, S.-G. (2002). The maize Crinkly4 gene is expressed spatially in vegetative and floral organs. J. Plant Biol. 45, 219-224. doi: 10.1007/ BF03030363

Kobe, B., and Deisenhofer, J. (1994). The leucine-rich repeat: a versatile binding motif. Trends Biochem. Sci. 19 (10), 415-421. doi: 10.1016/0968-0004(94) 90090-6

Kuhn, J. M., Boisson-Dernier, A., Dizon, M. B., Maktabi, M. H., and Schroeder, J. I. (2006). The protein phosphatase AtPP2CA negatively regulates abscisic acid signal transduction in Arabidopsis, and effects of abh1 on AtPP2CA mRNA. Plant Physiol. 140 (1), 127-139. doi: 10.1104/pp.105.070318

Kulik, A., Wawer, I., Krzywińska, E., Bucholc, M., and Dobrowolska, G. (2011). SnRK2 protein kinases--key regulators of plant response to abiotic stresses. OMICS. 15 (12), 859-872. doi: 10.1089/omi.2011.0091

Kumar, D., Kumar, R., Baek, D., Hyun, T. K., Chung, W. S., Yun, D. J., et al. (2017). Arabidopsis thaliana receptor dead kinasel functions as a positive regulator in plant responses to ABA. Mol. Plant 10 (2), 223-243. doi: 10.1016/j. molp.2016.11.011

Lee, I. C., Hong, S. W., Whang, S. S., Lim, P. O., Nam, H. G., and Koo, J. C. (2011). Age-dependent action of an ABA-inducible receptor kinase, RPK1, as a positive regulator of senescence in Arabidopsis leaves. Plant Cell Physiol. 52 (4), 651-662. doi: 10.1093/pcp/pcr026

Lee, S. C., Lim, C. W., Lan, W., He, K., and Luan, S. (2013). ABA signaling in guard cells entails a dynamic protein-protein interaction relay from the PYL-RCAR family receptors to ion channels. Mol. Plant 6 (2), 528-538. doi: 10.1093/mp/ sss078

Lim, P. O., Kim, H. J., and Nam, H. G. (2007). Leaf senescence. Annu. Rev. Plant Biol. 58, 115-136. doi: 10.1146/annurev.arplant.57.032905.105316

Liu, J. J., Sturrock, R., and Ekramoddoullah, A. K. (2010). The superfamily of thaumatin-like proteins: its origin, evolution, and expression towards biological function. Plant Cell Rep. 29 (5), 419-436. doi: 10.1007/s00299010-0826-8

Liu, X. M., Kim, K. E., Kim, K. C., Nguyen, X. C., Han, H. J., Jung, M. S., et al. (2010). Cadmium activates Arabidopsis MPK3 and MPK6 via accumulation of reactive oxygen species. Phytochemistry 71 (5-6), 614-618. doi: 10.1016/j. phytochem.2010.01.005

Loris, R., Imberty, A., Beeckmans, S., Van Driessche, E., Read, J. S., Bouckaert, J., et al. (2003). Crystal structure of Pterocarpus angolensis lectin in complex with glucose, sucrose, and turanose. J. Biol. Chem. 278 (18), 16297-16303. doi: 10.1074/jbc.M211148200

Ma, Y., Szostkiewicz, I., Korte, A., Moes, D., Yang, Y., Christmann, A., et al. (2009). Regulators of PP2C phosphatase activity function as abscisic acid sensors. Science 324 (5930), 1064-1068. doi: 10.1126/science.1172408

Mandel, T., Candela, H., Landau, U., Asis, L., Zelinger, E., Carles, C. C., et al. (2016). Differential regulation of meristem size, morphology and organization by the ERECTA, CLAVATA and class III HD-ZIP pathways. Development 143 (9), 1612-1622. doi: 10.1242/dev.129973

McCarty, D. R., and Chory, J. (2000). Conservation and innovation in plant signaling pathways. Cell 103 (2), 201-209. doi: 10.1016/S0092-8674(00)00113-6

Melcher, K., Ng, L. M., Zhou, X. E., Soon, F. F., Xu, Y., Suino-Powell, K. M., et al. (2009). A gate-latch-lock mechanism for hormone signalling by abscisic acid receptors. Nature 462 (7273), 602-608. doi: 10.1038/nature08613

Misra, R. C., Sandeep, Kamthan, M., Kumar, S., and Ghosh, S. (2016). A thaumatin-like protein of Ocimum basilicum confers tolerance to fungal pathogen and abiotic stress in transgenic Arabidopsis. Sci. Rep. 6, 25340. doi: $10.1038 /$ srep25340

Ng, L. M., Soon, F. F., Zhou, X. E., West, G. M., Kovach, A., Suino-Powell, K. M., et al. (2011). Structural basis for basal activity and autoactivation of abscisic acid (ABA) signaling SnRK2 kinases. Proc. Natl. Acad. Sci. U.S.A. 108 (52), 21259-21264. doi: 10.1073/pnas.1118651109

Nikonorova, N., Vu, L. D., Czyzewicz, N., Gevaert, K., and De Smet, I. (2015). A phylogenetic approach to study the origin and evolution of the CRINKLY4 family. Front. Plant Sci. 6, 880. doi: 10.3389/fpls.2015.00880
Nishimura, N., Hitomi, K., Arvai, A. S., Rambo, R. P., Hitomi, C., Cutler, S. R., et al. (2009). Structural mechanism of abscisic acid binding and signaling by dimeric PYR1. Science 326 (5958), 1373-1379. doi: 10.1126/science.1181829

Nishimura, N., Sarkeshik, A., Nito, K., Park, S. Y., Wang, A., Carvalho, P. C., et al. (2010). PYR/PYL/RCAR family members are major in-vivo ABI1 protein phosphatase 2C-interacting proteins in Arabidopsis. Plant J. 61 (2), 290-299. doi: 10.1111/j.1365-313X.2009.04054.x

Osakabe, Y., Maruyama, K., Seki, M., Satou, M., Shinozaki, K., and YamaguchiShinozaki, K. (2005). Leucine-rich repeat receptor-like kinasel is a key membrane-bound regulator of abscisic acid early signaling in Arabidopsis. Plant Cell 17 (4), 1105-1119. doi: 10.1105/tpc.104.027474

Park, S. Y., Fung, P., Nishimura, N., Jensen, D. R., Fujii, H., Zhao, Y., et al. (2009). Abscisic acid inhibits type $2 \mathrm{C}$ protein phosphatases via the PYR/PYL family of START proteins. Science 324 (5930), 1068-1071. doi: 10.1126/science.1173041

Raghavendra, A. S., Gonugunta, V. K., Christmann, A., and Grill, E. (2010). ABA perception and signalling. Trends Plant Sci. 15 (7), 395-401. doi: 10.1016/j. tplants.2010.04.006

Rivero, R. M., Kojima, M., Gepstein, A., Sakakibara, H., Mittler, R., Gepstein, S., et al. (2007). Delayed leaf senescence induces extreme drought tolerance in a flowering plant. Proc. Natl. Acad. Sci. U.S.A. 104 (49), 19631-19636. doi: 10.1073/pnas.0709453104

Roychoudhury, A., Paul, S., and Basu, S. (2013). Cross-talk between abscisic aciddependent and abscisic acid-independent pathways during abiotic stress. Plant Cell Rep. 32 (7), 985-1006. doi: 10.1007/s00299-013-1414-5

Saez, A., Robert, N., Maktabi, M. H., Schroeder, J. I., Serrano, R., and Rodriguez, P. L. (2006). Enhancement of abscisic acid sensitivity and reduction of water consumption in Arabidopsis by combined inactivation of the protein phosphatases type 2C ABI1 and HAB1. Plant Physiol. 141 (4), 1389-1399. doi: $10.1104 /$ pp. 106.081018

Schoof, H., Lenhard, M., Haecker, A., Mayer, K. F., Jürgens, G., and Laux, T. (2000). The stem cell population of Arabidopsis shoot meristems in maintained by a regulatory loop between the CLAVATA and WUSCHEL genes. Cell 100 (6), 635-644. doi: 10.1016/S0092-8674(00)80700-X

Shang, Y., Dai, C., Lee, M. M., Kwak, J. M., and Nam, K. H. (2016). BRI1-associated receptor kinase 1 regulates guard cell $\mathrm{ABA}$ signaling mediated by open stomata 1 in Arabidopsis. Mol. Plant 9 (3), 447-460. doi: 10.1016/j.molp.2015.12.014

Shiu, S. H., and Bleecker, A. B. (2001). Receptor-like kinases from Arabidopsis form a monophyletic gene family related to animal receptor kinases. Proc. Natl. Acad. Sci. U.S.A. 98, 10763-10768. doi: 10.1073/pnas.181141598

Singh, N. K., Handa, A. K., Hasegawa, P. M., and Bressan, R. A. (1985). Proteins associated with adaptation of cultured tobacco cells to NaCl. Plant Physiol. 79, 126-137. doi: 10.1104/pp.79.1.126

Singh, N. K., LaRosa, P. C., Handa, A. K., Hasegawa, P. M., and Bressan, R. A. (1987). Hormonal regulation of protein synthesis associated with salt tolerance in plant cells. Proc. Natl. Acad. Sci. U.S.A. 84, 739-743. doi: 10.1073/ pnas.84.3.739

Singh, N. K., Nelson, D. E., Kuhn, D., Hasegawa, P. M., and Bressan, R. A. (1989). Molecular cloning of osmotin and regulation of its expression by $\mathrm{ABA}$ and adaptation to low water potential. Plant Physiol. 90 (3), 1096-1101. doi: 10.1104/pp.90.3.1096

Takayama, S., and Isogai, A. (2003). Molecular mechanism of self-recognition in Brassica self-incompatibility. J. Exp. Bot. 54 (380), 149-156. doi: 10.1093/jxb/ $\operatorname{erg} 007$

Tanaka, H., Osakabe, Y., Katsura, S., Mizuno, S., Maruyama, K., Kusakabe, K., et al. (2012). Abiotic stress-inducible receptor-like kinases negatively control ABA signaling in Arabidopsis. Plant J. 70 (4), 599-613. doi: 10.1111/j.1365-313X.2012.04901.x

Thomma, B. P., Eggermont, K., Penninckx, I. A., Mauch-Mani, B., Vogelsang, R., Cammue, B. P., et al. (1998). Separate jasmonate-dependent and salicylatedependent defense-response pathways in Arabidopsis are essential for resistance to distinct microbial pathogens. Proc. Natl. Acad. Sci. U.S.A. 95 (25), 15107-15111. doi: 10.1073/pnas.95.25.15107

Tian, G., Lu, Q., Zhang, L., Kohalmi, S. E., and Cui, Y. (2011). Detection of protein interactions in plant using a gateway compatible bimolecular fluorescence complementation (BiFC) system. J. Vis. Exp. (55), e3473. doi: $10.3791 / 3473$

Tian, Q., Olsen, L., Sun, B., Lid, S. E., Brown, R. C., Lemmon, B. E., et al. (2007). Subcellular localization and functional domain studies of DEFECTIVE 
KERNEL1 in maize and Arabidopsis suggest a model for aleurone cell fate specification involving CRINKLY4 and SUPERNUMERARY ALEURONE LAYER1. Plant Cell 19, 3127-3145. doi: 10.1105/tpc.106.048868

Torii, K. U., Mitsukawa, N., Oosumi, T., Matsuura, Y., Yokoyama, R., Whittier, R. F., et al. (1996). The Arabidopsis ERECTA gene encodes a putative receptor protein kinase with extracellular leucine-rich repeats. Plant Cell 8 (4), 735-746. doi: $10.1105 /$ tpc.8.4.735

Umezawa, T., Nakashima, K., Miyakawa, T., Kuromori, T., Tanokura, M., Shinozaki, K., et al. (2009b). Molecular basis of the core regulatory network in ABA responses: sensing, signaling and transport. Plant Cell Physiol. 51 (11), 1821-1839. doi: $10.1093 /$ pcp/pcq156

Umezawa, T., Sugiyama, N., Mizoguchi, M., Hayashi, S., Myouga, F., YamaguchiShinozaki, K., et al. (2009a). Type 2C protein phosphatases directly regulate abscisic acid-activated protein kinases in Arabidopsis. Proc. Natl. Acad. Sci. U.S.A. 106 (41), 17588-17593. doi: 10.1073/pnas.0907095106

Vaid, N., Pandey, P. K., and Tuteja, N. (2012). Genome-wide analysis of lectin receptor-like kinase family from Arabidopsis and rice. Plant Mol. Biol. 80, 365388. doi: 10.1007/s11103-012-9952-8

van Loon, L. C., Rep, M., and Pieterse, C. M. (2006). Significance of inducible defense-related proteins in infected plants. Annu. Rev. Phytopathol. 44, 135162. doi: 10.1146/annurev.phyto.44.070505.143425

Verica, J. A., and He, Z. H. (2002). The cell wall-associated kinase (WAK) and WAKlike kinase gene family. Plant Physiol. 129 (2), 455-459. doi: 10.1104/pp.011028

Verica, J. A., Chae, L., Tong, H., Ingmire, P., and He, Z. H. (2003). Tissue-specific and developmentally regulated expression of a cluster of tandemly arrayed cell wall-associated kinase-like kinase genes in Arabidopsis. Plant Physiol. 133 (4), 1732-1746. doi: 10.1104/pp.103.028530

Wang, N., Huang, H. J., Ren, S. T., Li, J. J., Sun, Y., Sun, D. Y., et al. (2012). The rice wallassociated receptor-like kinase gene OsDEES1 plays a role in female gametophyte development. Plant Physiol. 160 (2), 696-707. doi: 10.1104/pp.112.203943

Wang, X., Zafian, P., Choudhary, M., and Lawton, M. (1996). The PR5K receptor protein kinase from Arabidopsis thaliana is structurally related to a family of plant defense proteins. Proc. Natl. Acad. Sci. U.S.A. 93 (6), 2598-2602. doi: 10.1073/pnas.93.6.2598

Xie, T., Ren, R., Zhang, Y. Y., Pang, Y., Yan, C., Gong, X., et al. (2012). Molecular mechanism for inhibition of a critical component in the Arabidopsis thaliana abscisic acid signal transduction pathways, SnRK2.6, by protein phosphatase ABI1. J. Biol. Chem. 287 (1), 794-802. doi: 10.1074/jbc.M111.313106

Yang, Y., Labbé, J., Muchero, W., Yang, X., Jawdy, S. S., Kennedy, M., et al. (2016). Genome-wide analysis of lectin receptor-like kinases in Populus. BMC Genomics 17, 699. doi: 10.1186/s12864-016-3026-2

Yin, P., Fan, H., Hao, Q., Yuan, X., Wu, D., Pang, Y., et al. (2009). Structural insights into the mechanism of abscisic acid signaling by PYL proteins. Nat. Struct. Mol. Biol. 16 (12), 1230-1236. doi: 10.1038/nsmb.1730
Yokoyama, R., Takahashi, T., Kato, A., Torii, K. U., and Komeda, Y. (1998). The Arabidopsis ERECTA gene is expressed in the shoot apical meristem and organ primordia. Plant J. 15 (3), 301-310. doi: 10.1046/j. 1365-313X.1998.00203.x

Yoshida, R., Umezawa, T., Mizoguchi, T., Takahashi, S., Takahashi, F., and Shinozaki, K. (2006a). The regulatory domain of SRK2E/OST1/SnRK2.6 interacts with $\mathrm{ABI} 1$ and integrates abscisic acid (ABA) and osmotic stress signals controlling stomatal closure in Arabidopsis. J. Biol. Chem. 281 (8), 5310-5318. doi: 10.1074/jbc.M50982020

Yoshida, T., Fujita, Y., Sayama, H., Kidokoro, S., Maruyama, K., Mizoi, J., et al. (2010). AREB1, AREB2, and ABF3 are master transcription factors that cooperatively regulate ABRE-dependent $\mathrm{ABA}$ signaling involved in drought stress tolerance and require ABA for full activation. Plant J. 61 (4), 672-685. doi: 10.1111/j.1365-313X.2009.04092.x

Yoshida, T., Nishimura, N., Kitahata, N., Kuromori, T., Ito, T., Asami, T., et al. (2006b). ABA-hypersensitive germination 3 encodes a protein phosphatase $2 \mathrm{C}$ (AtPP2CA) that strongly regulates abscisic acid signaling during germination among Arabidopsis protein phosphatase 2Cs. Plant Physiol. 140 (1), 115-126. doi: 10.1104/pp.105.070128

Yun, D. J., Ibeas, J. I., Lee, H., Coca, M. A., Narasimhan, M. L., Uesono, Y., et al. (1998). Osmotin, a plant antifungal protein, subverts signal transduction to enhance fungal cell susceptibility. Mol. Cell 1 (6), 807-817. doi: 10.1016/ S1097-2765(00)80080-5

Yun, D. J., Zhao, Y., Pardo, J. M., Narasimhan, M. L., Damsz, B., Lee, H., et al. (1997). Stress proteins on the yeast cell surface determine resistance to osmotin, a plant antifungal protein. Proc. Natl. Acad. Sci. U.S.A. 94 (13), 7082-7087. doi: 10.1073/pnas.94.13.7082

Zhao, Y., Chan, Z., Gao, J., Xing, L., Cao, M., Yu, C., et al. (2016). ABA receptor PYL9 promotes drought resistance and leaf senescence. Proc. Natl. Acad. Sci. U.S.A. 113 (7), 1949-1954. doi: 10.1073/pnas.1522840113

Zhu, J.-K. (2002). Salt and drought stress signal transduction in plants. Annu Rev Plant Biol. 53, 247-273.

Conflict of Interest: The authors declare that the research was conducted in the absence of any commercial or financial relationships that could be construed as a potential conflict of interest.

Copyright $\odot 2019$ Baek, Kim, Kumar, Park, Cheong, Choi, Park, Chun, Park, Lee, Bressan, Kim and Yun. This is an open-access article distributed under the terms of the Creative Commons Attribution License (CC BY). The use, distribution or reproduction in other forums is permitted, provided the original author(s) and the copyright owner(s) are credited and that the original publication in this journal is cited, in accordance with accepted academic practice. No use, distribution or reproduction is permitted which does not comply with these terms. 